Jaber Jerboa FAHD ${ }^{1}$

\title{
MORPHOLOGICAL EXPLANATION AND ITS DEVELOPMENT IN THE TRANSMITTED FROM THE WORDS OF ARABS AND SCHOLARS
}

\section{Istanbul/ Türkiye}

\section{p. $29-42$}

\section{Article Information}

Article Type: Research Article

This article was checked by

iThenticate No plagiarism detected

\section{Article History}

Received: $21 / 10 / 2020$

Accepted: $13 / 11 / 2020$

published: 01/12/2020

\begin{abstract}
:
The morphological reasoning is based on what was transmitted from the words of Arabs and scholars and how were the manifestations of development in this explanation. It came from that story. Then I moved on to those who came after them from among the scholars of grammar and morphology, and shed light on their interest in explanation and their interest in it, and how their books and compilations were full of explanation for all the issues raised in them. Morphological explanations, which are concerned with explanations for morphological issues exclusively.

This research came in varying formats, and this matter was imposed by the nature of the scientific material in it. For morphological issues in particular, the research material focused on the second topic, which was specialized in explanation in the morphological books that were classified in the first five centuries of the history of Arabic grammar, so it was necessary to divide it into two sections that branched into other branches and divisions.
\end{abstract}

Key words: Morphological Explanation; Scholars; Words of Arabs.

http://dx.doi.org/10.47832/2791-9323.1-1.3

Dr. , Karkh Third Directorate - Ministry of Education, Iraq, Jabr.arabic77@gmail.com, https://orcid.org/0000-0002$\underline{5106-5053}$ 


\section{التَّعليل الصَّرَيّ وتطوره في المنقول من كلام العرب والعلماء}

\section{جبر جربوع فهد 2}

\section{الملخص}

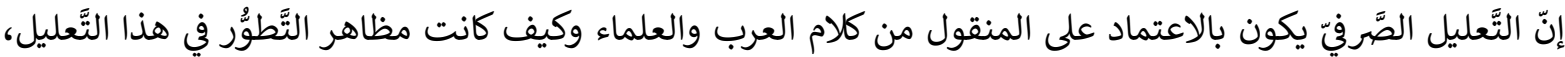

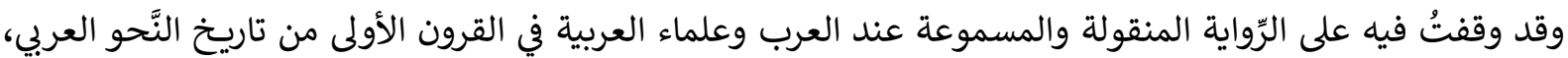

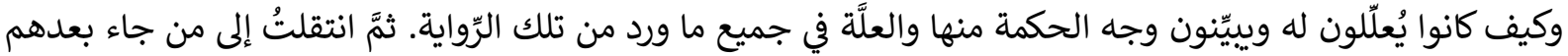

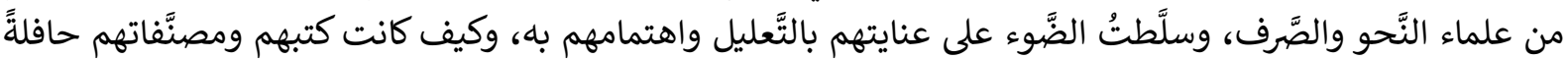

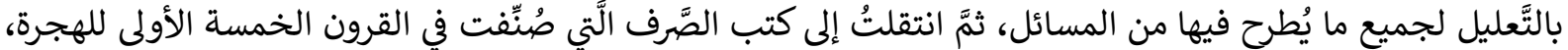

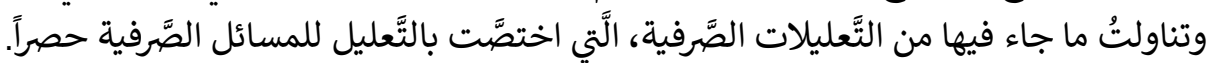

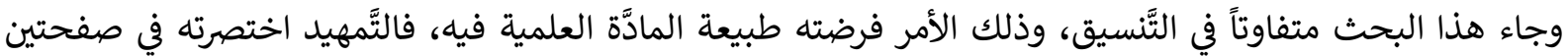

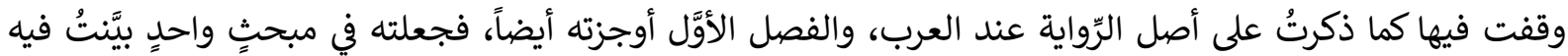

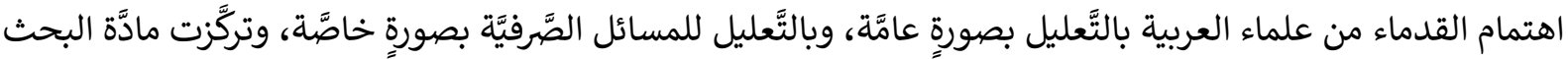

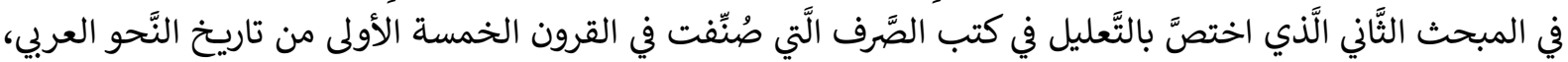

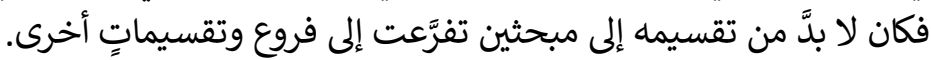

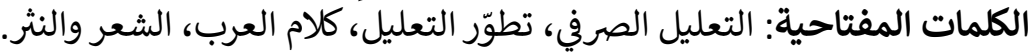

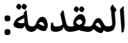

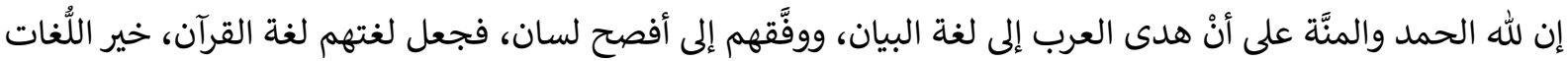

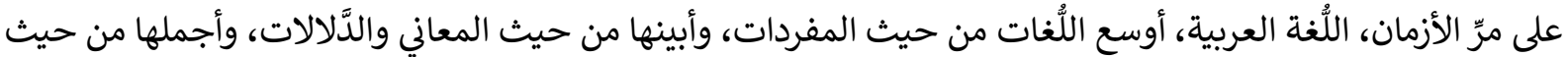

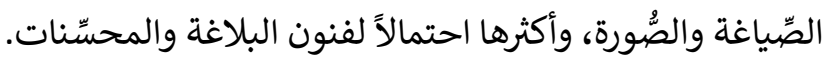

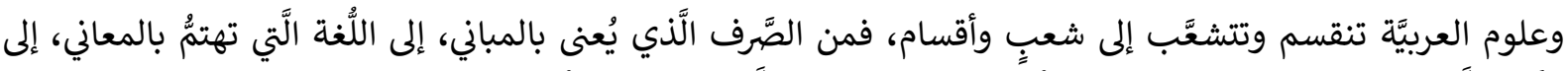

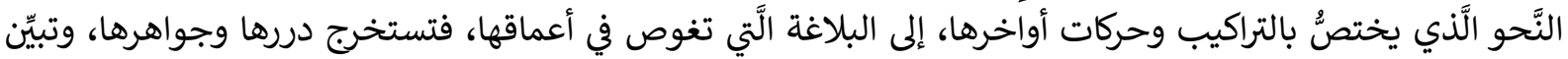
جمال صورها وحسن أساليبها.

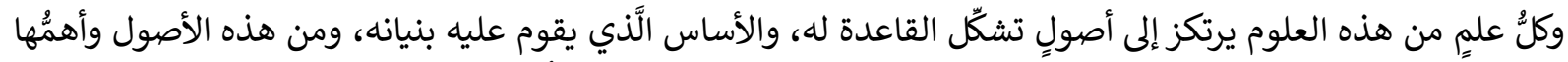

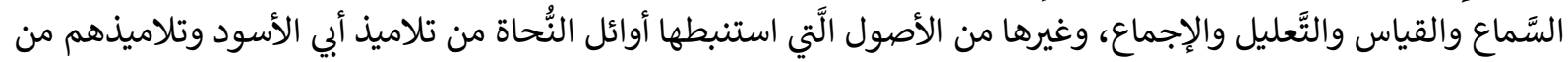

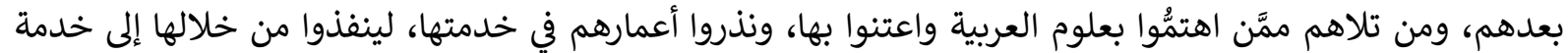

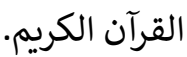
وللتَّعليل خصوآن الكريمِّة تميِّه على هذه الأصول، فهو وإنْ عُدَّ قسماً من هذه الأصول، وأصلاً مستقلاً منفرداً بنفسه، إلَّا أنَّهَ

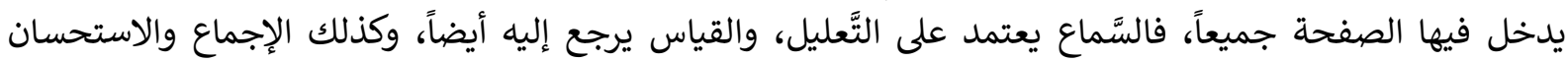

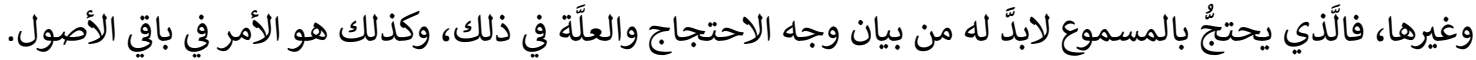

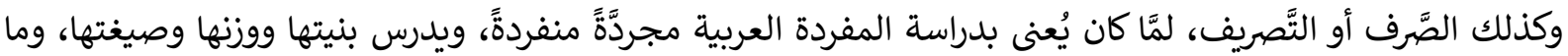

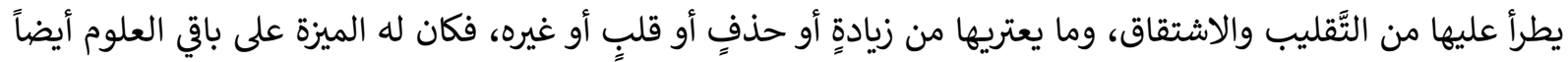
حتَّى قال بعض العلماء: الصَّرف أمُّم العلوم.

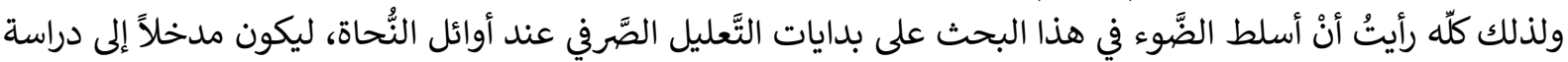

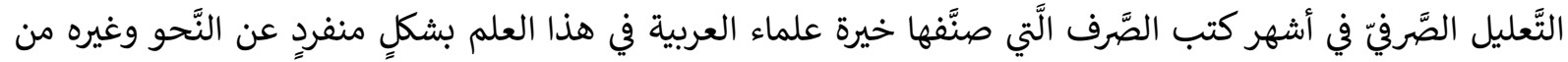


علوم العربية منذ أنْ وضع أبو عثمان المازني (ت 249هـ)، حتَّى نهاية القرن الخامس الهجري، والَّني اختتم بالشَّيخ عبد القاهر الجرجاني، ومؤلَّفاته الصَّرفية.

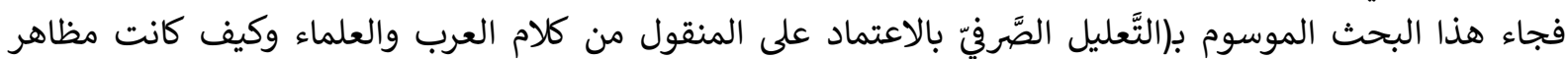

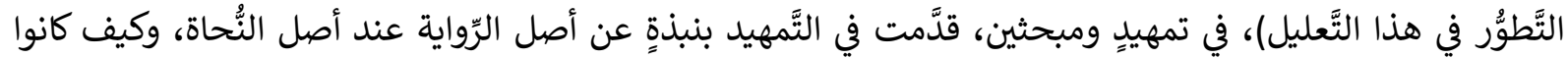

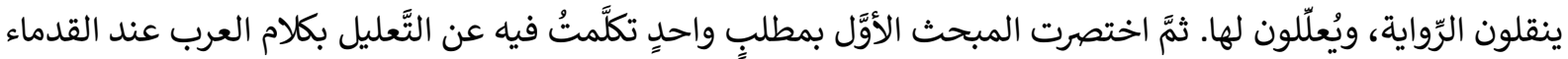

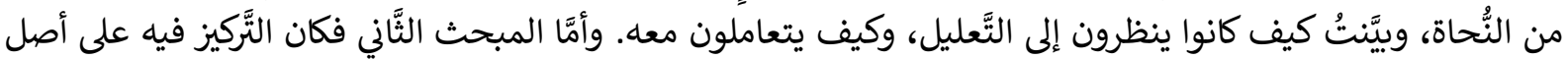

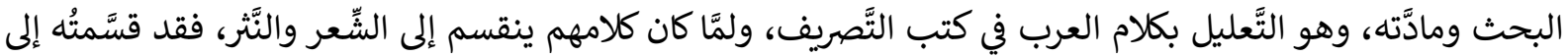

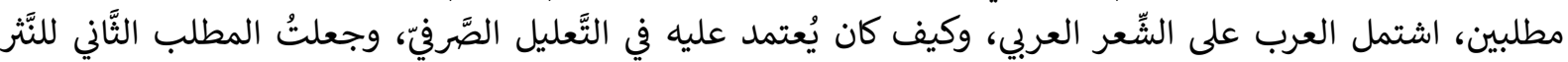

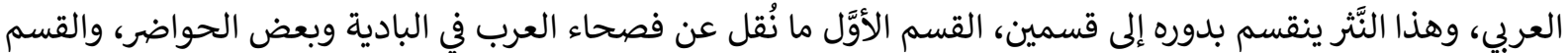

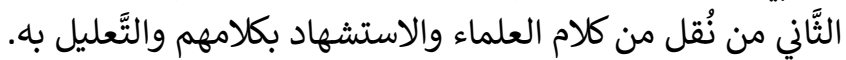

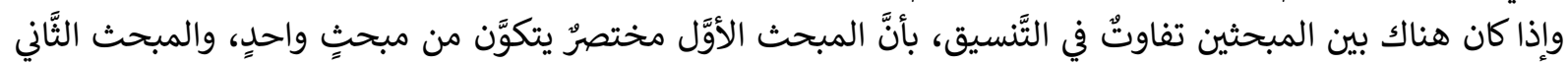

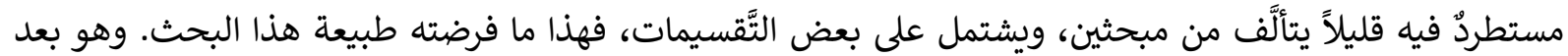

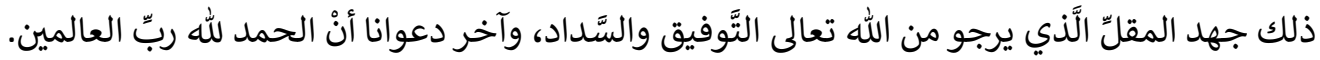

\section{نبذةٌ عن أصل الرّرواية عند أوائل النُحاة:}

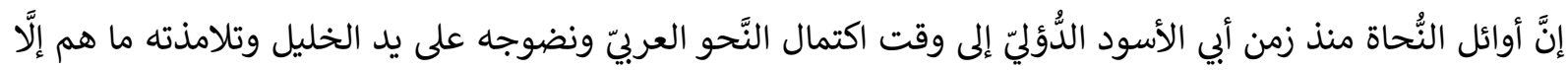

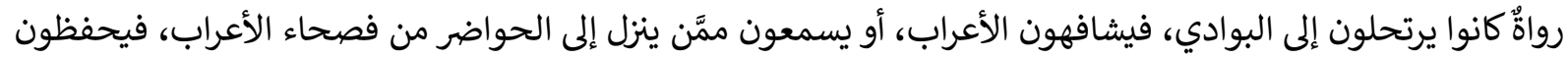

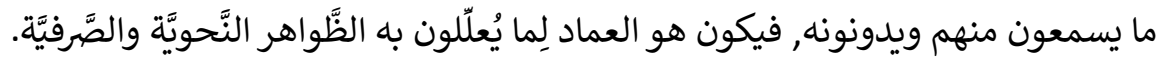

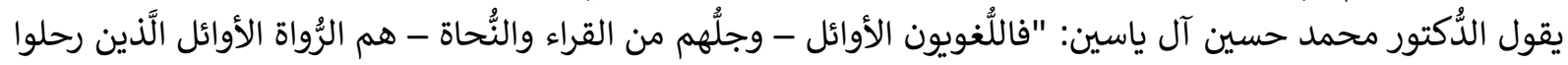

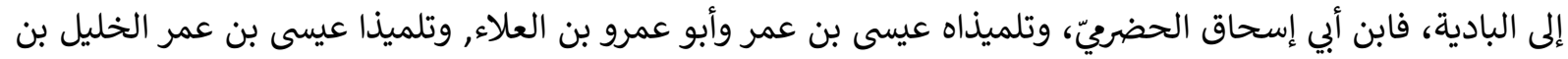

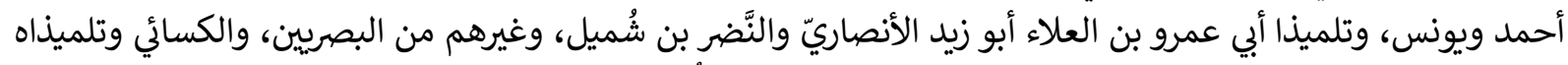

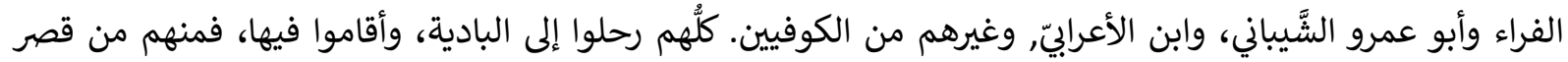

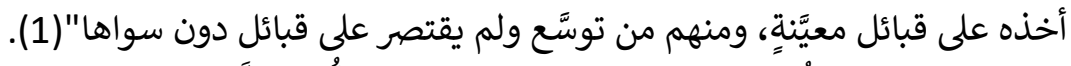

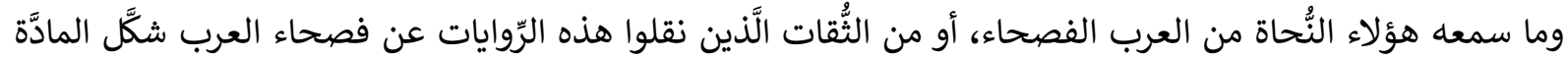

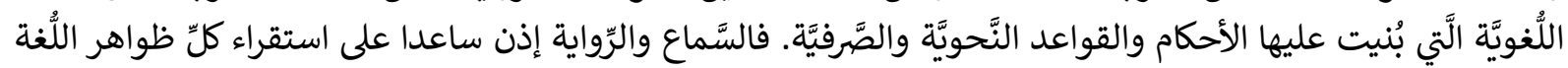
وجمعها، وحفظ الموروث اللُّويّي

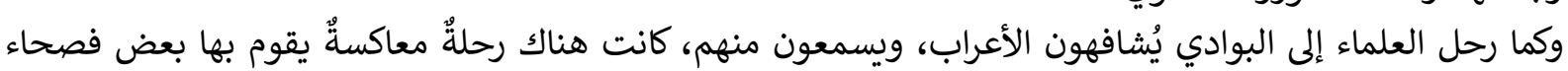

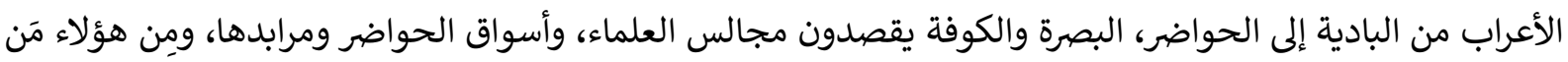

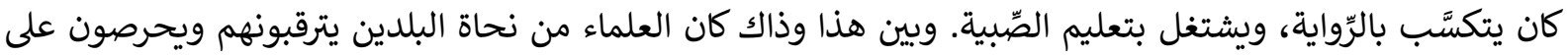

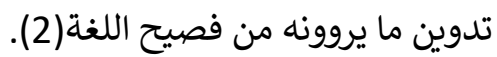

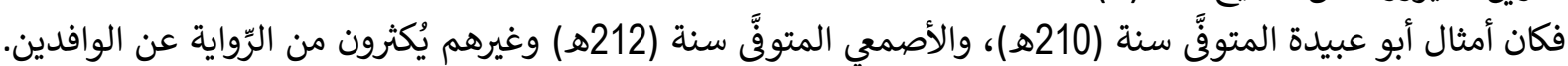

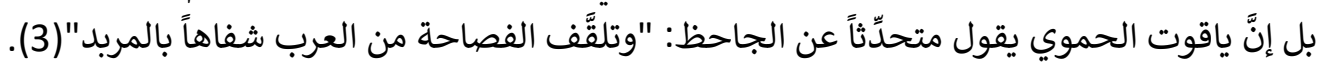

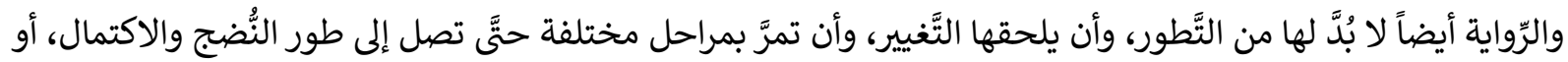

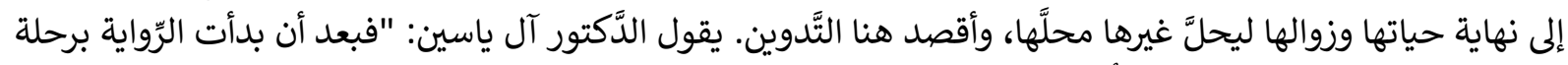

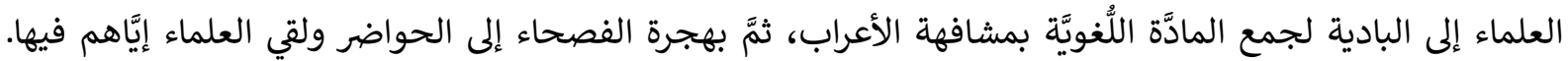

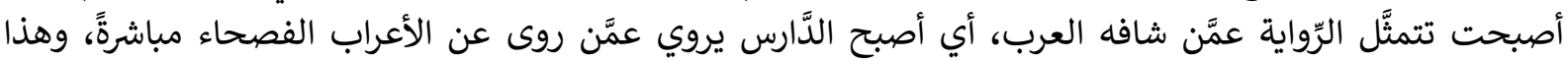

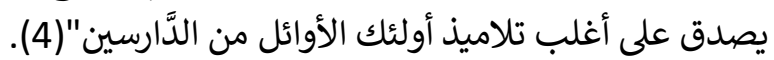

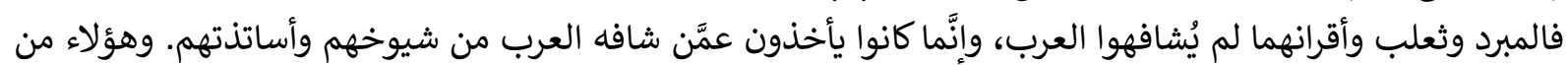

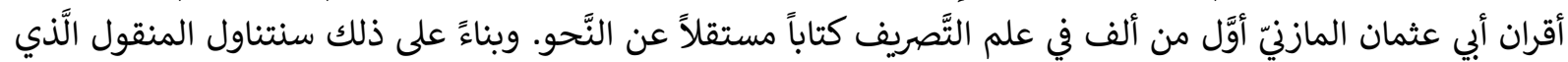

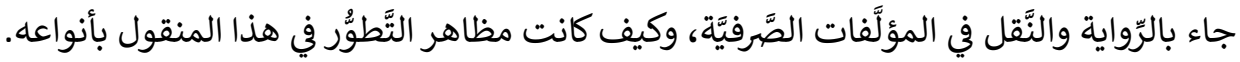




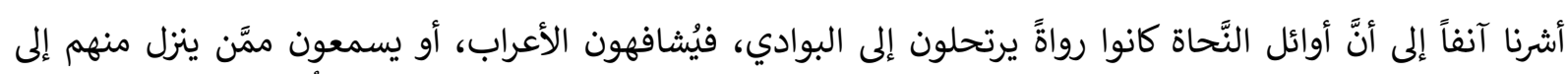

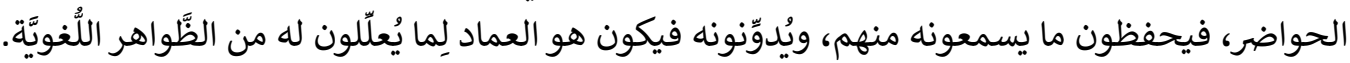

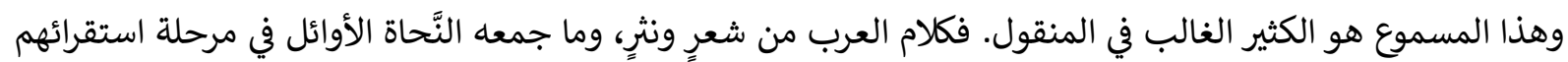

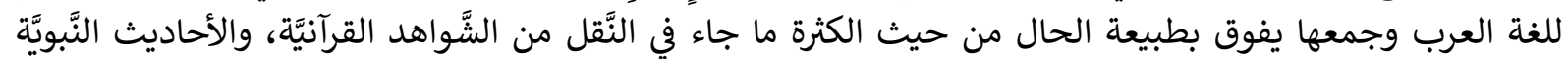
مجتمعةً.

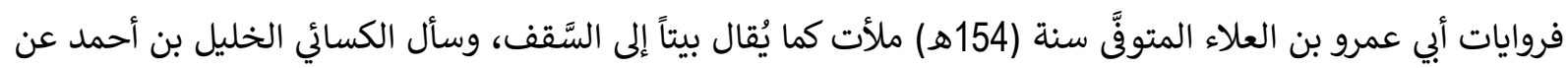

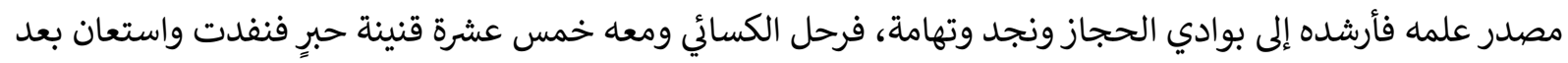

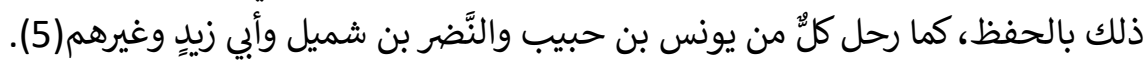

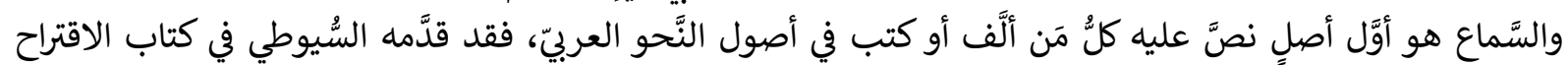

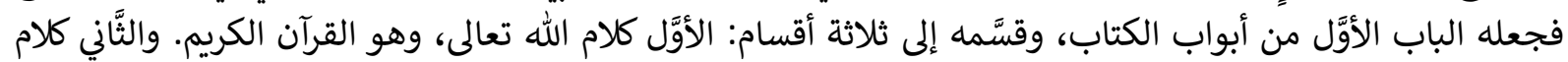

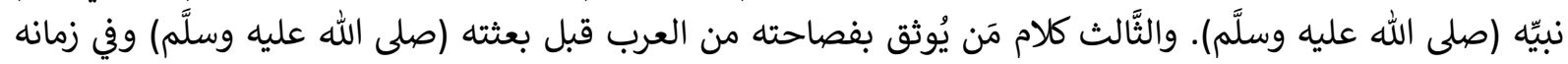

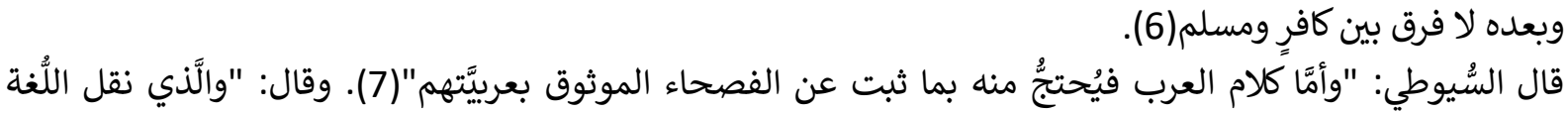

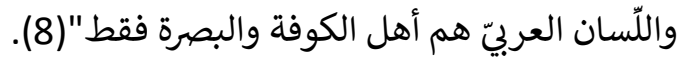

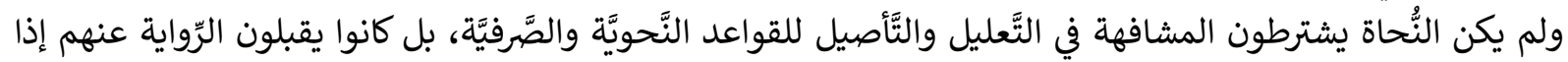

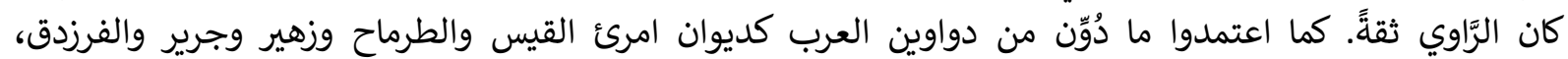
وغيرهم(9).

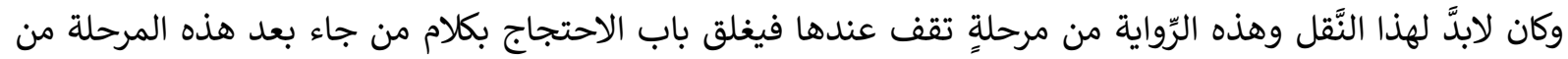

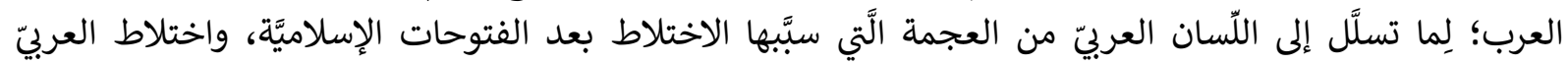

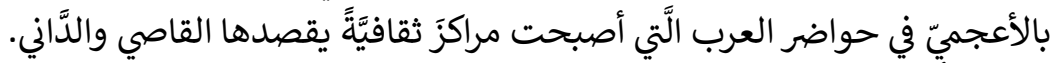

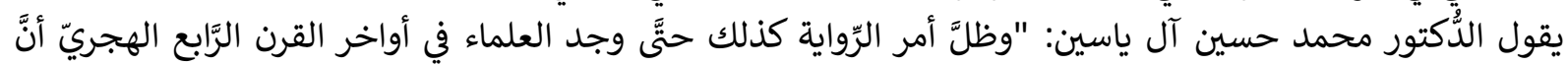

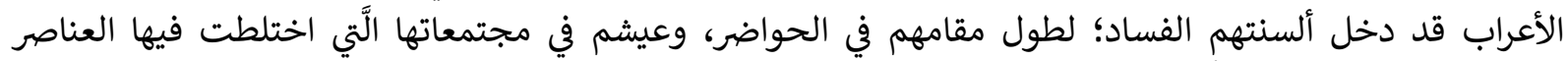

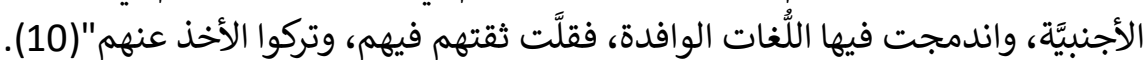

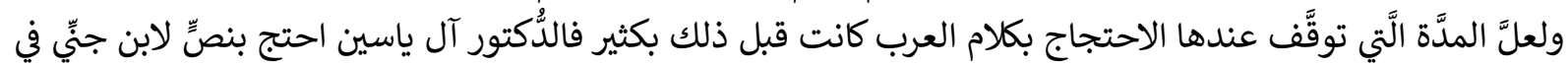

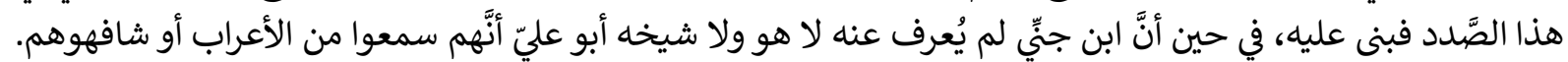

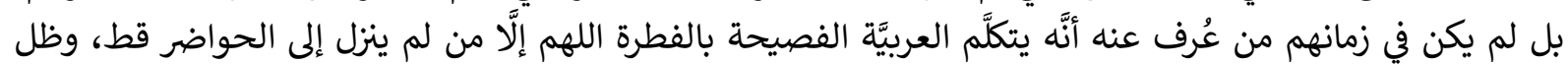
محافظاً على سليقته.

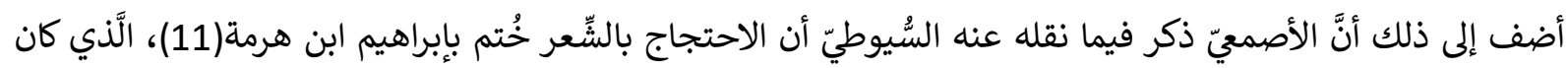

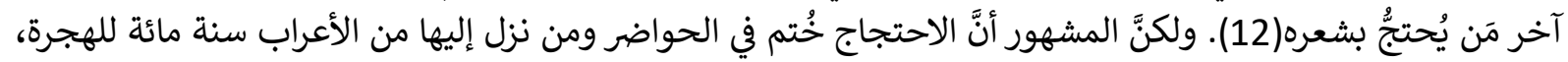

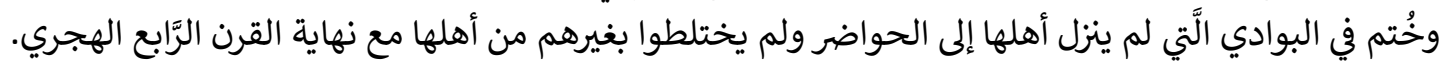

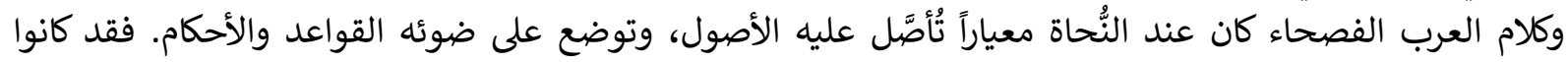

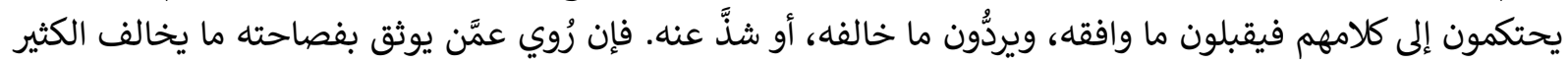

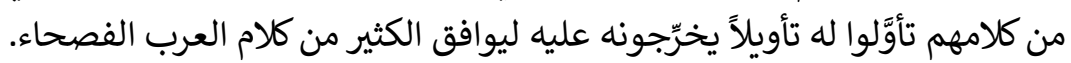

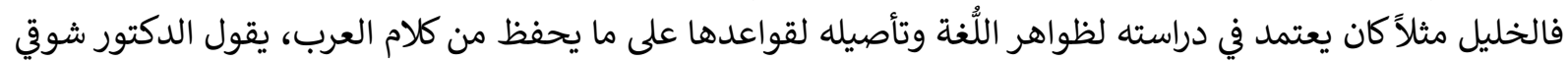

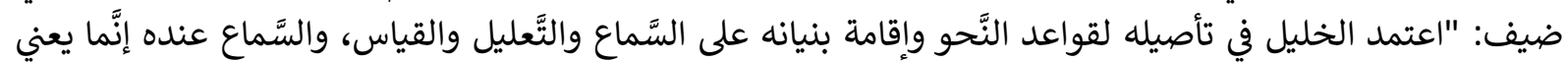

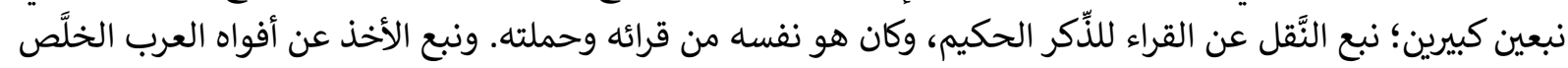

الَّذين يُوثق بفصاحتهم" (13). 
ولم يخرج سيبويه عن هذه الأسس الثلاثة الَّتي ذكرها شوقي ضيف، فقد كان يجري في السَّماع على الأساس الَّني وضعته

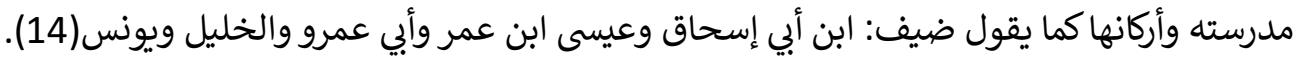

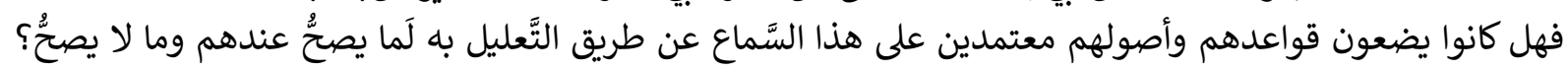

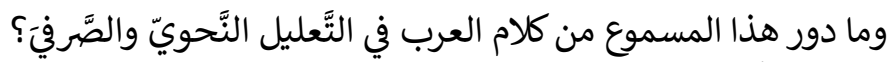

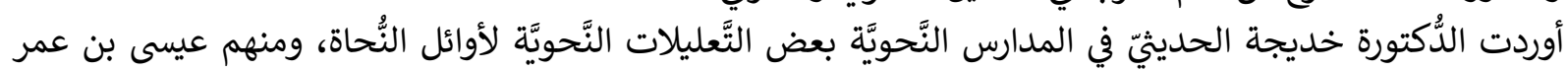

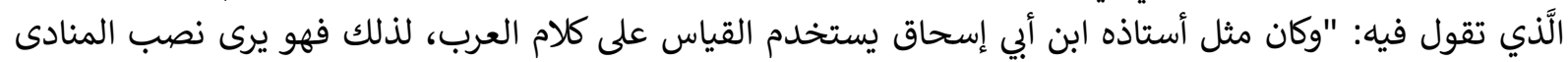

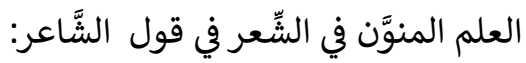

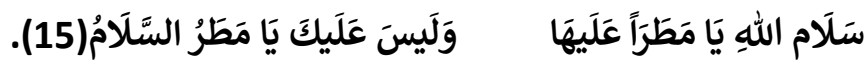

ويستخدم التَّعليل لذلك فيقول: (وذلك لأنَّهَ يُنوَّن، ومن شأن التَّنوين أن يردَّه إلى الأصل)"(16).

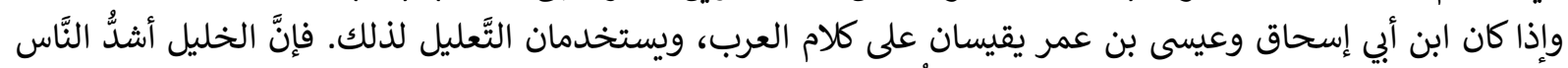

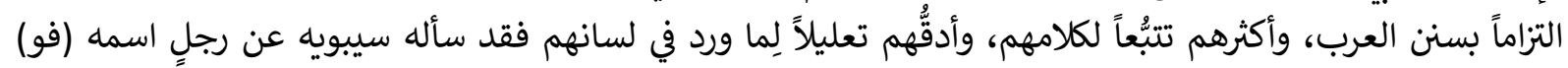

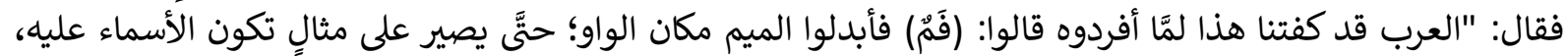

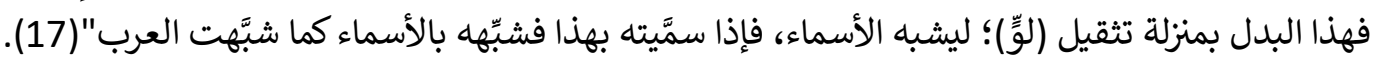

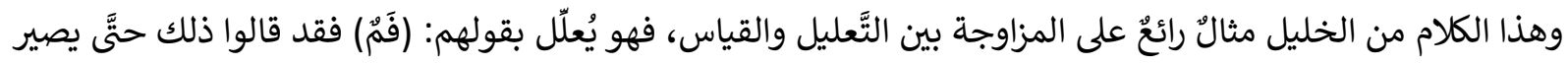

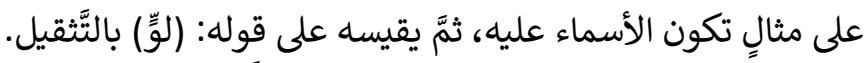

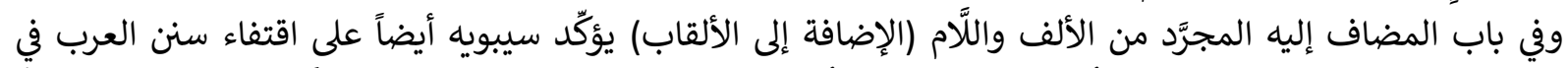

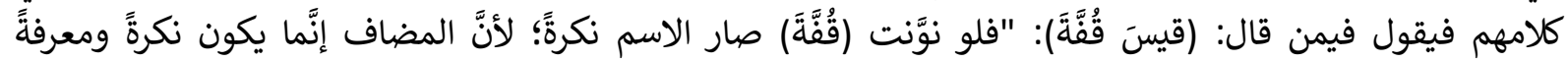

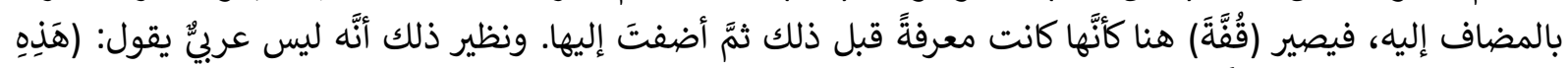

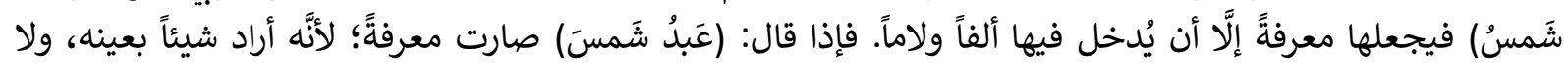

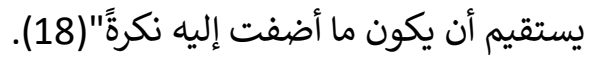

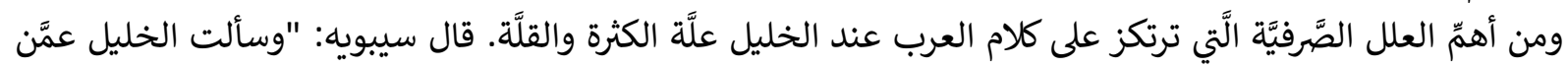

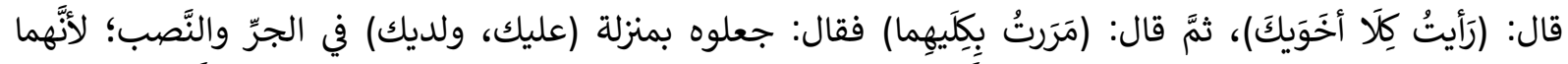

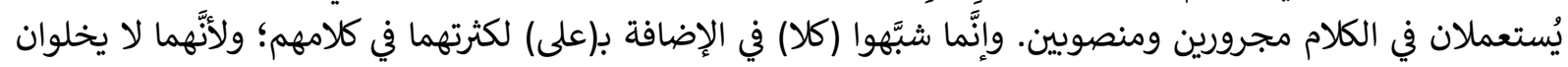
من الإضافة" (19).

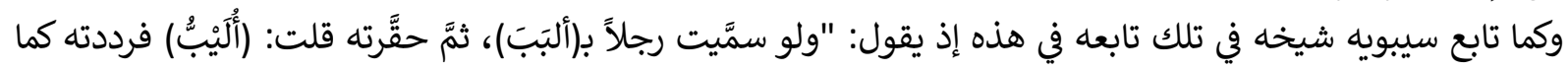

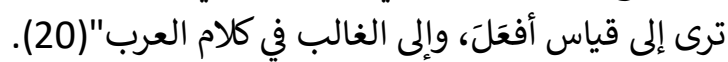

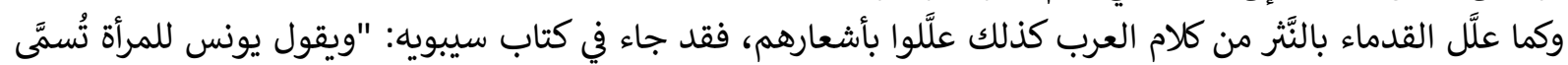

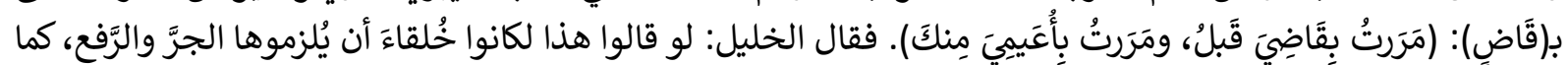

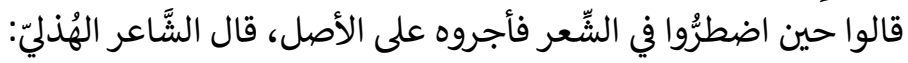

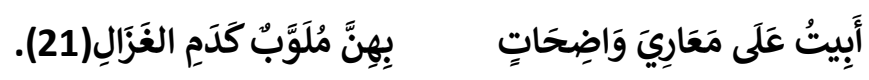
وقال الفرزدق:

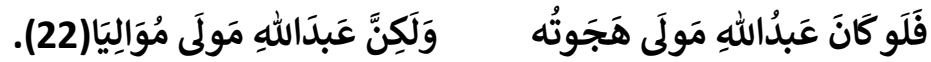

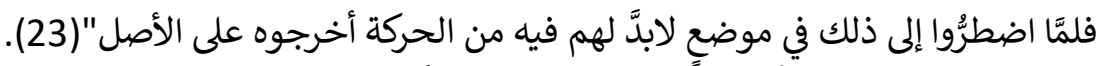

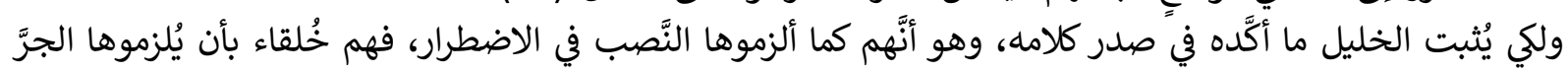

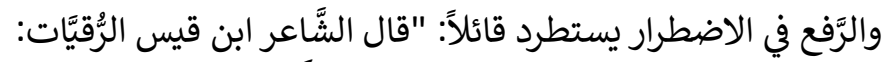

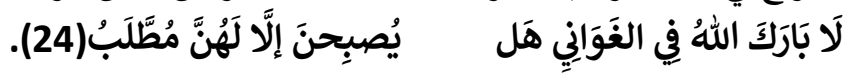

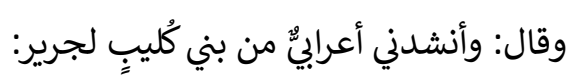

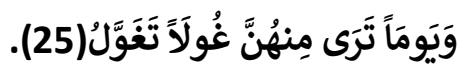
فَيَومَاً يُوَافِينَ الهَوَى غَيَرَ مَاضِي قال: ألا تراهم كيف جرُّوا حين اضطرُّوا كما نصبوا الأوَّل حين اضطرُّوا، وهذا الجرُّ نظير ذلك النَّصب"(26). 


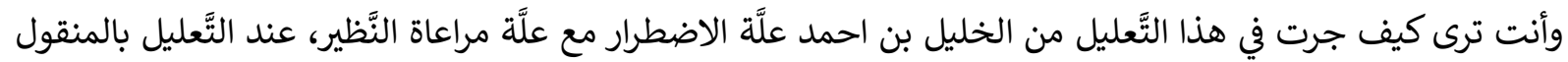

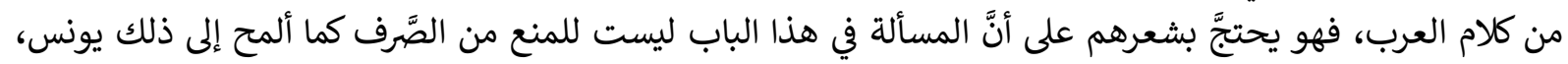

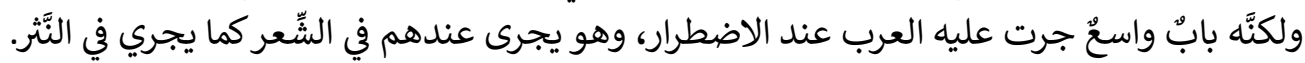

\section{المبحث الثَّاني : التعليل بكلام العرب- الشعر والنثر تقديـم: التَّعليل بكلام العرب في كتب التَّصريف:}

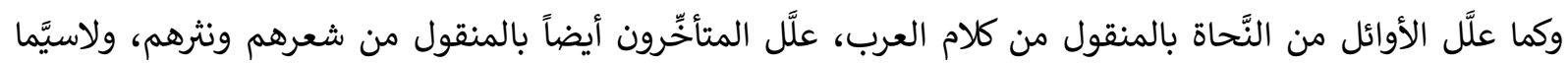

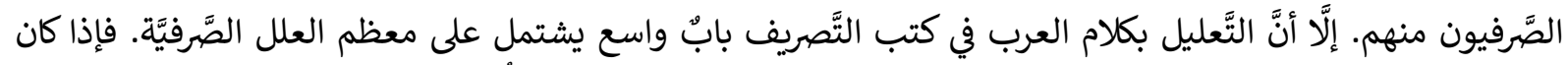

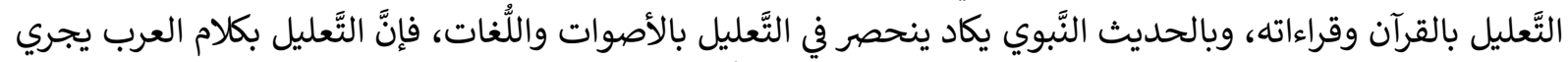

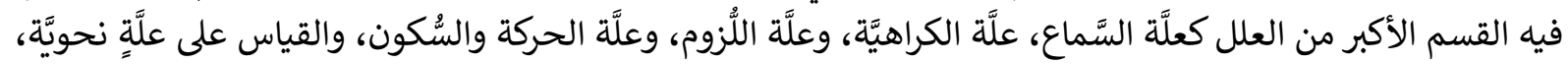

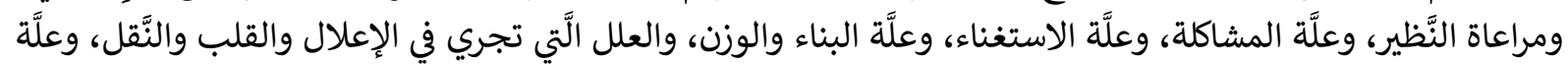

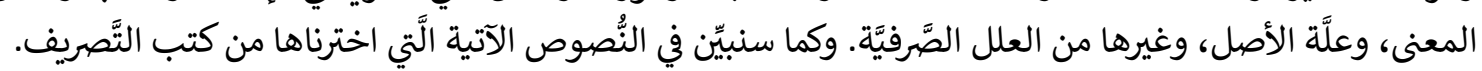

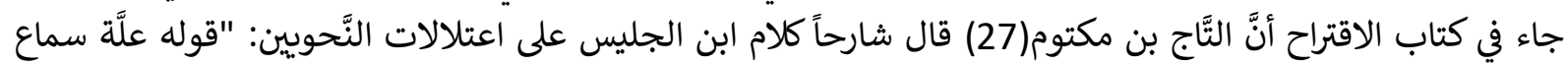

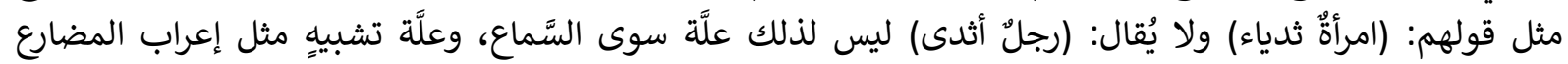

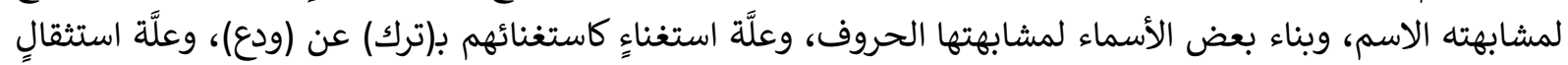

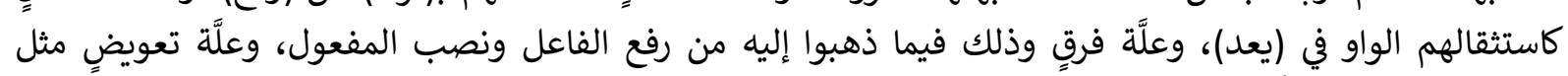

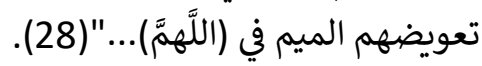

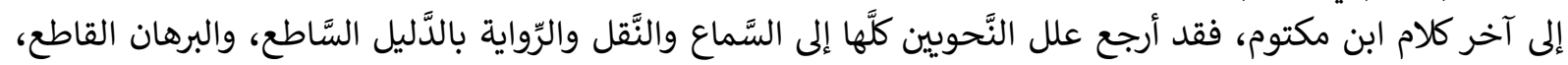

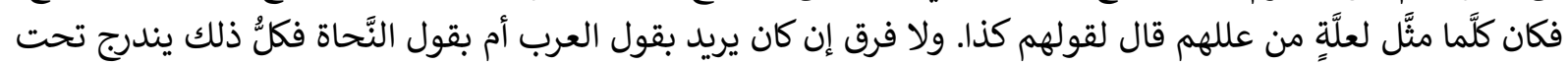

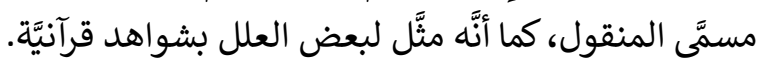

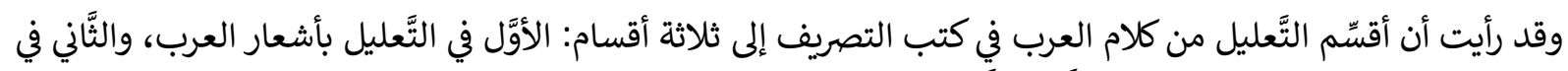

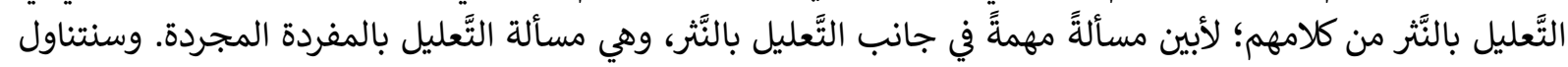

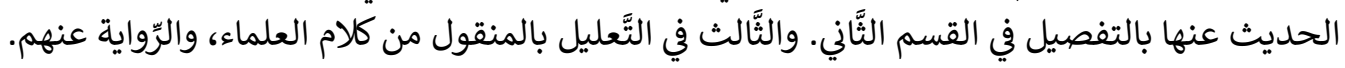

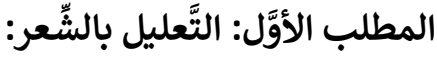

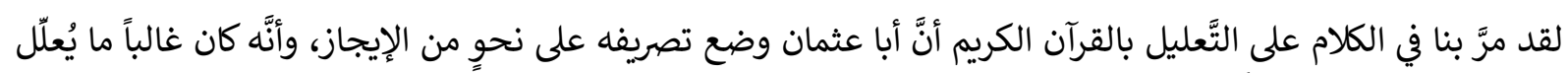

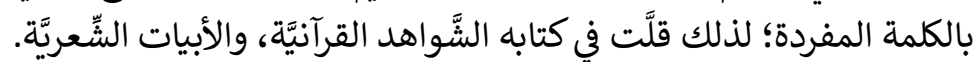

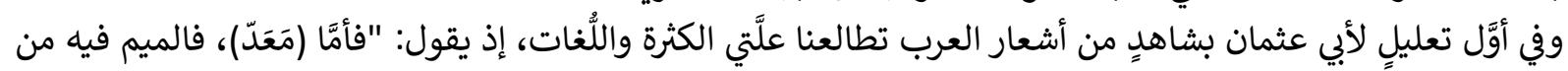

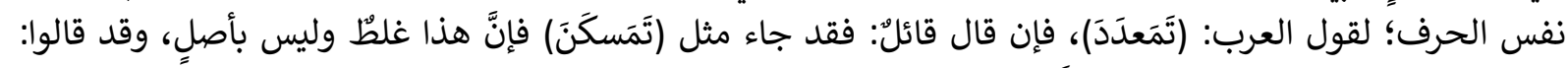

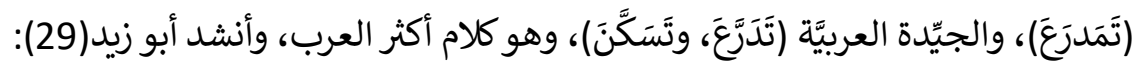

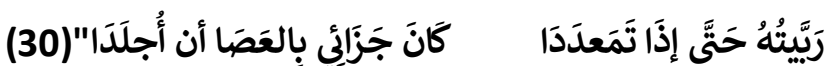

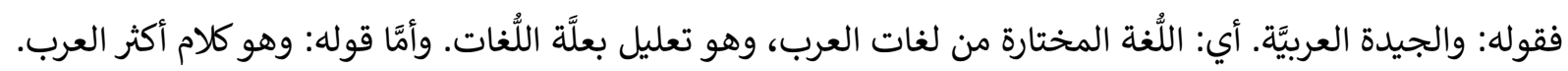
فلا يحتاج إلى تفسير، فقد صيَّح بعلَّة الكثرة.

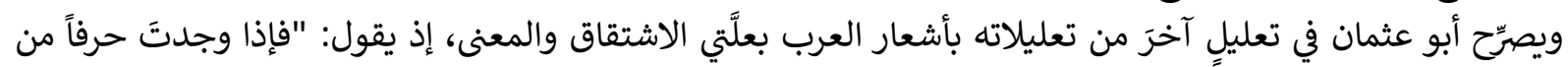

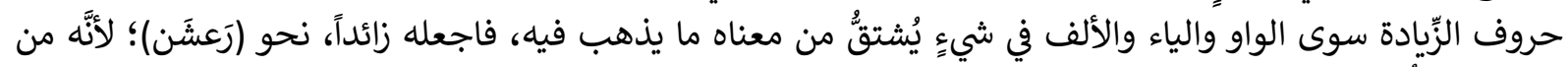

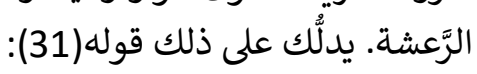
مِن كُلِّ رَعشَاءَ وَنَاجِ رَعََنِّ. 


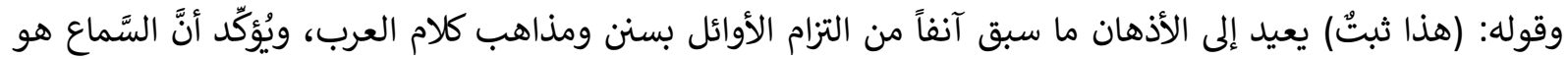

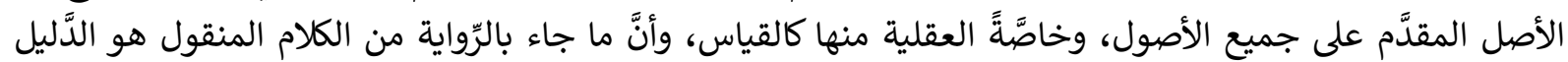

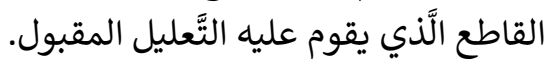

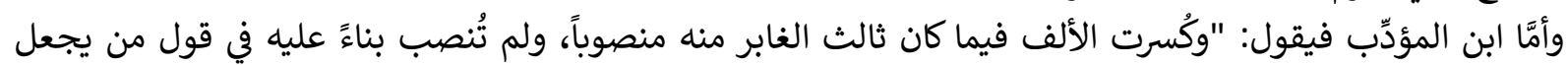

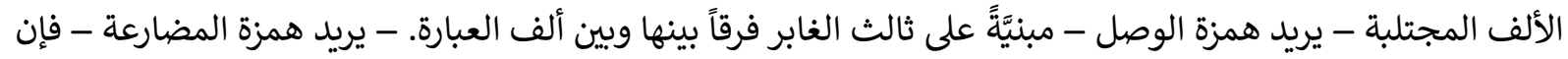

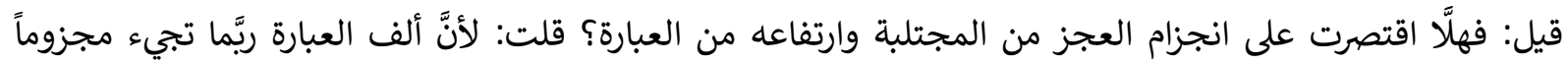

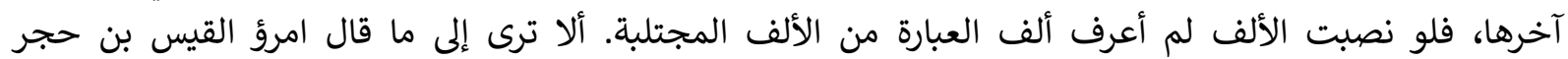

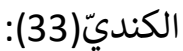

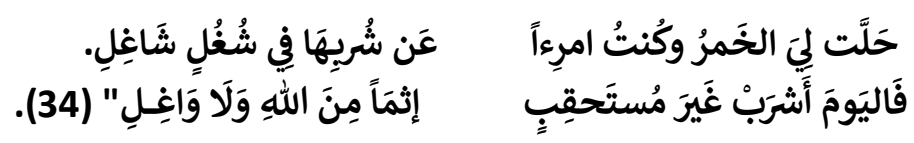

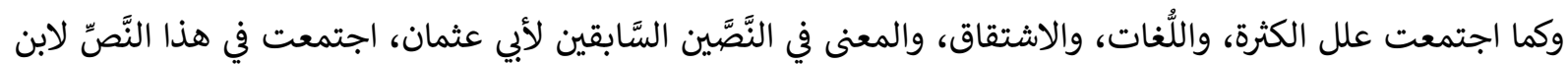

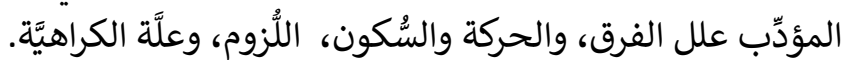

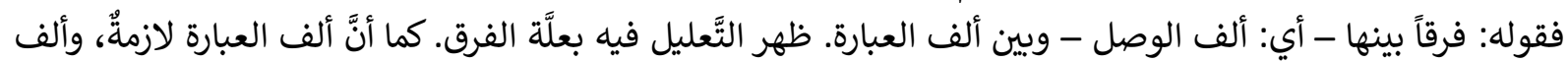

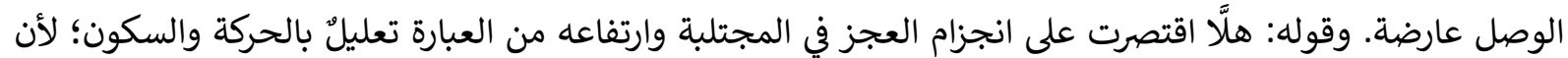
الجزم سكونٌ والرَّفع حركةٌ.

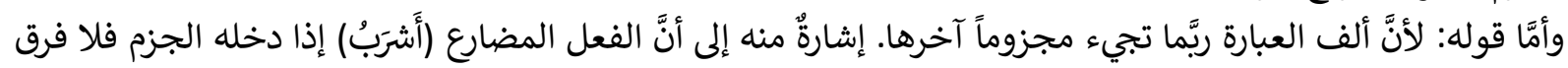

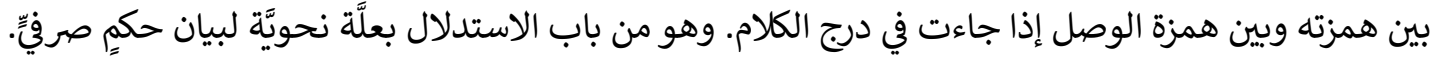

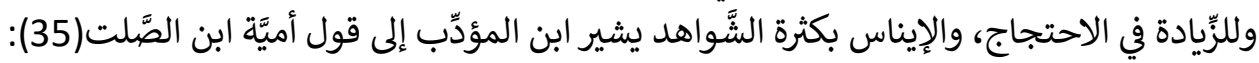

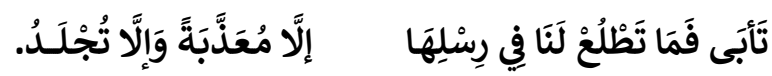

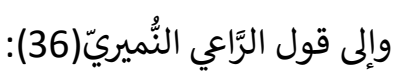

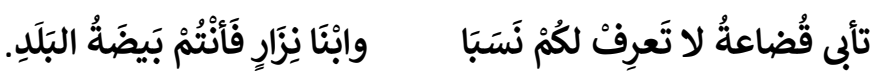
وإلى قول كُثِيٍِّ(

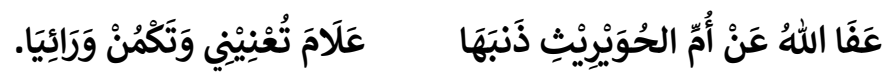
ثنَّ يخلص ابن المؤدِّب أنَّ تسكين أواخر الأفعال: (أشرب، وتطلع، وتعرف، وتكن) إنَّما هو لغير علَّةٍ توجب ذلك، ولكنَّه في الغالب لكراهية توالي الحركات(38).

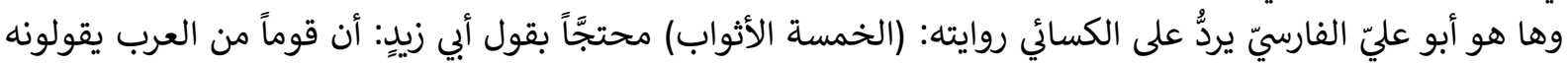

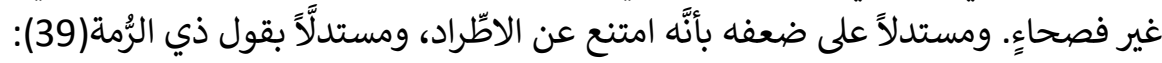

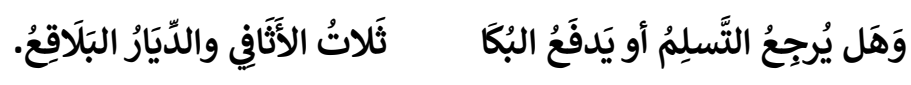

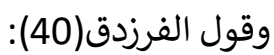

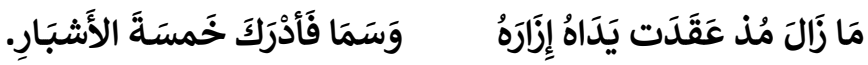

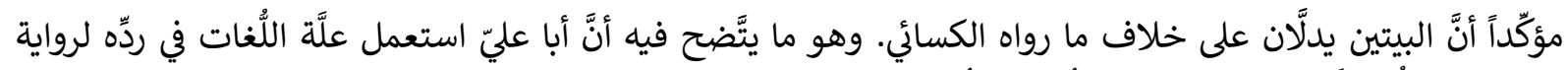

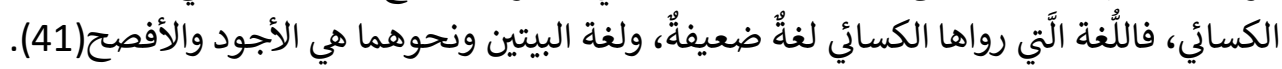

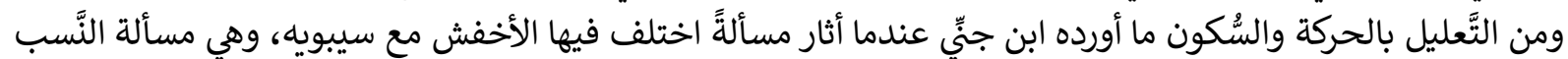

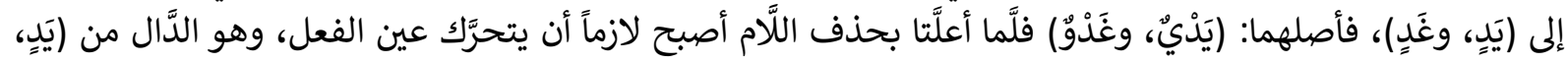

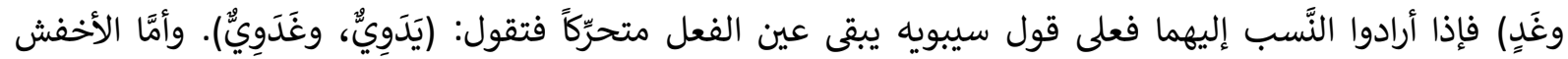

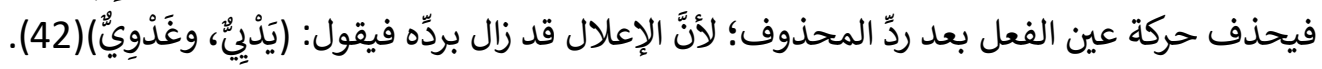




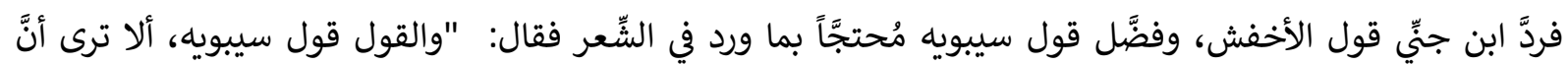

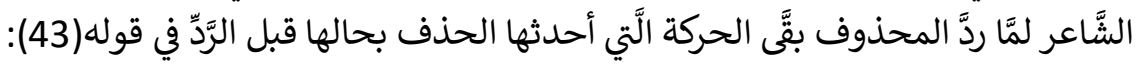

\section{يَدَيَانِ بَيضَاوَانِ عِندَ مُحَلَّهِ}

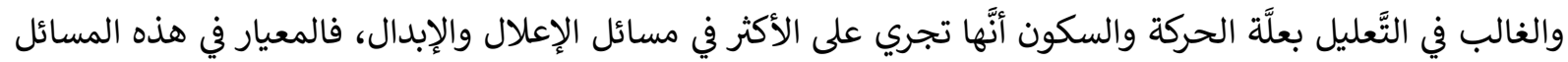

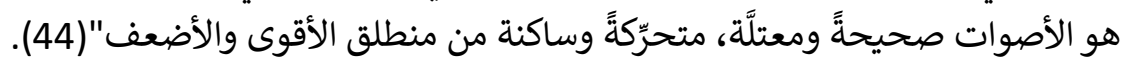

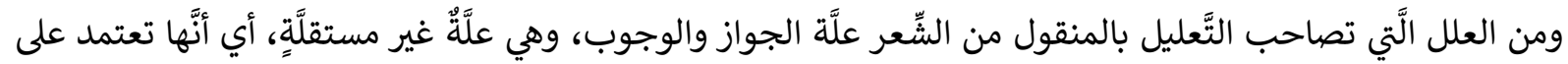

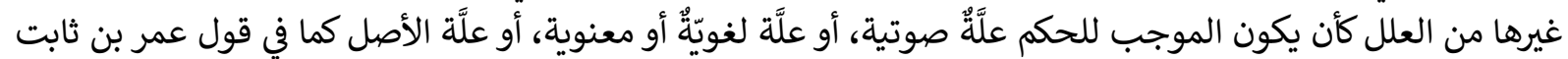

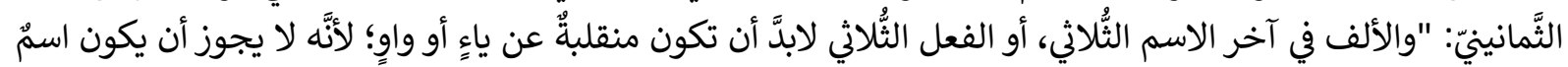

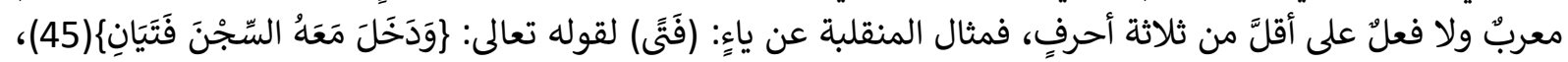

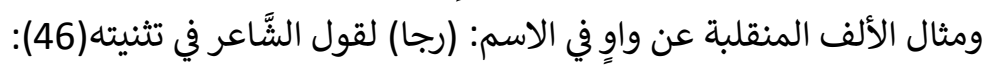

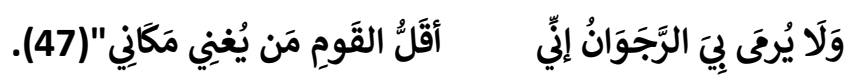

$$
\text { 1- المطلب الثَّاني: }
$$

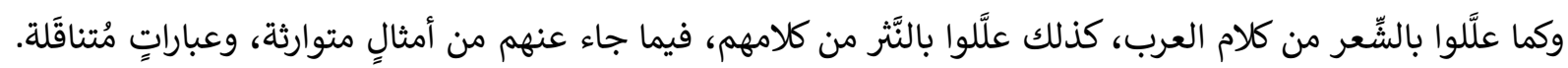

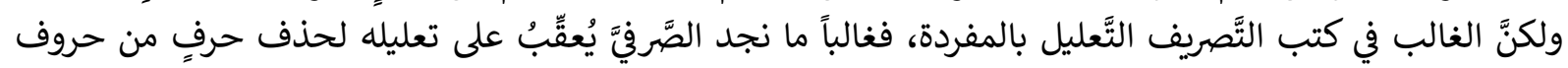

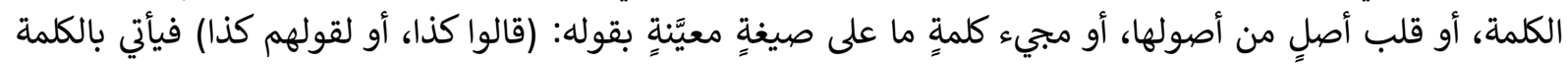

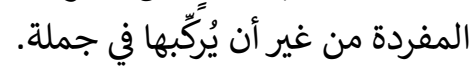

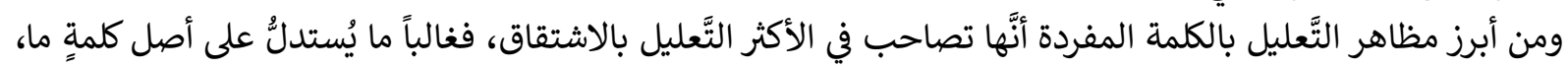

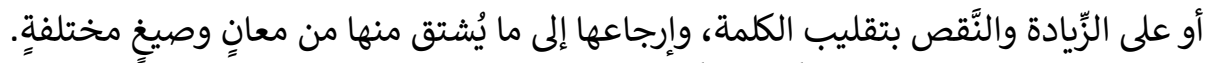

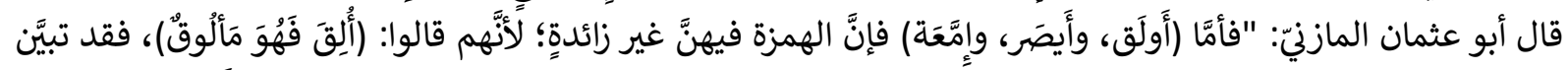

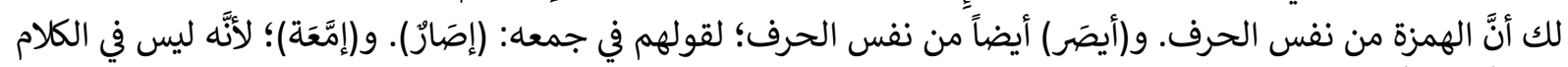

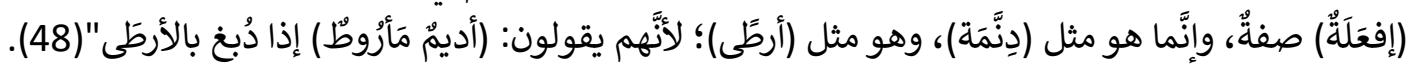

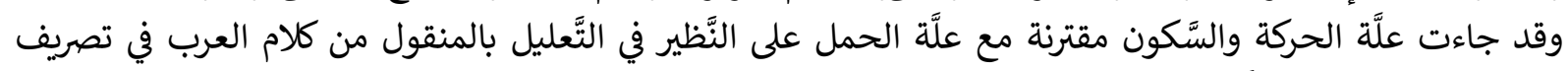

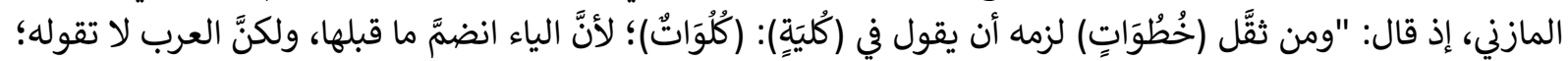

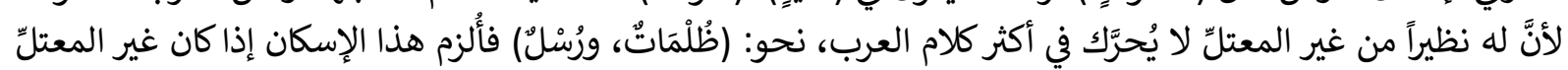

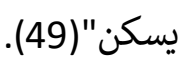
ومن التَّعليل بالمنقول من كلام العرب المنثور تخريج ابن المؤدِّب لقول رسول الله (صلى الله عليه وسلَّم): (موزورات)

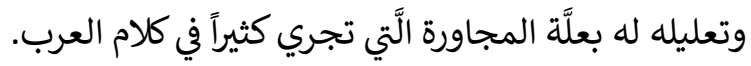

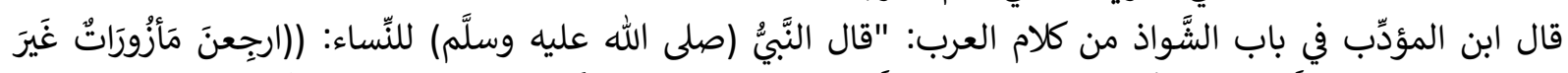

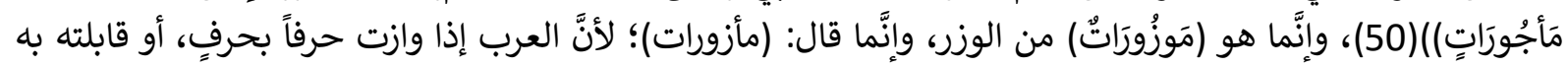

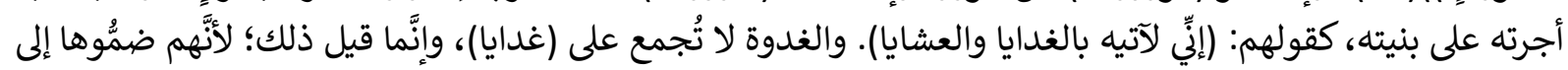

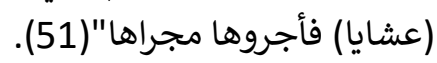

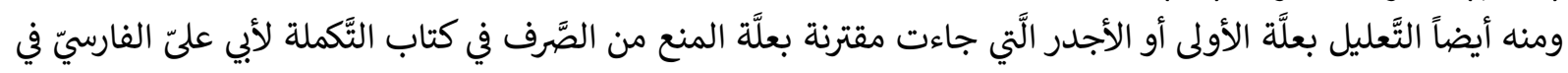

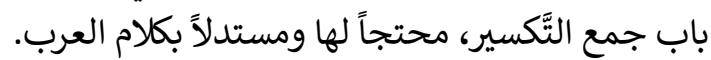

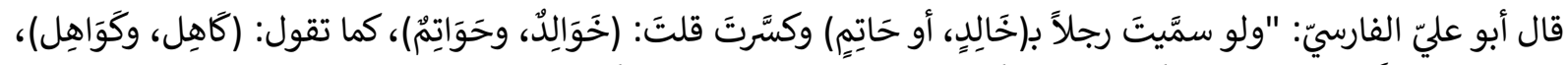

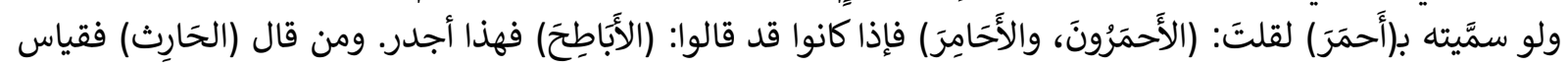




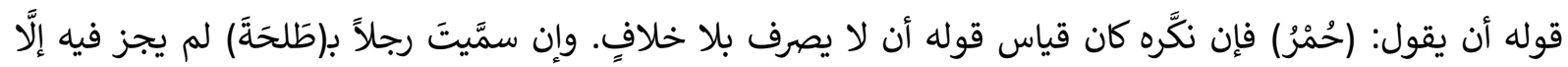

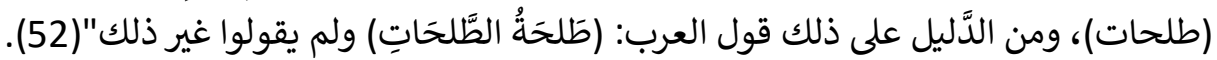

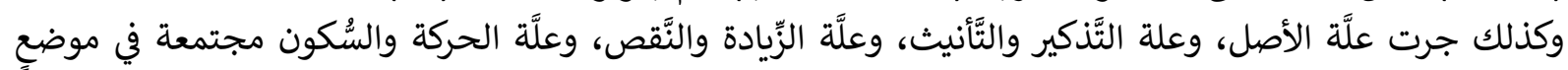

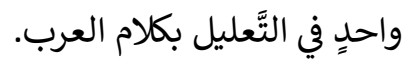

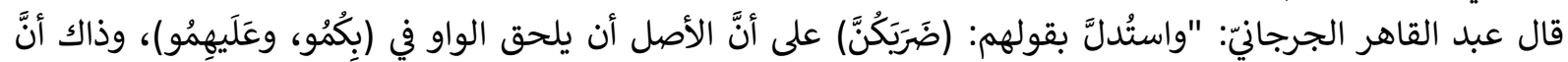

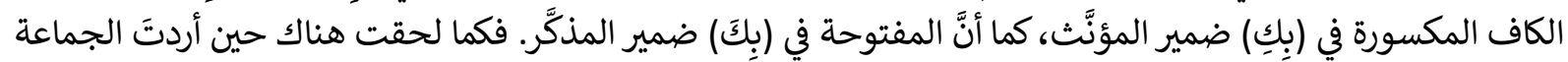

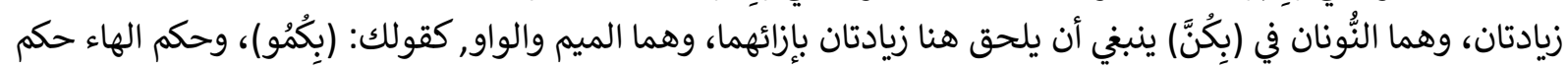

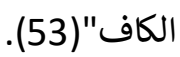

ولعلَّ أبرز مظاهر التَّطوُّر في قضيَّة التَّعليل بما ورد من كلام العرب عند بعض المتأَِّّرين تخطئة العرب في بناءٍ بنوه، أو أو

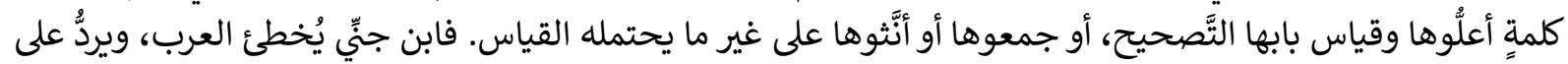

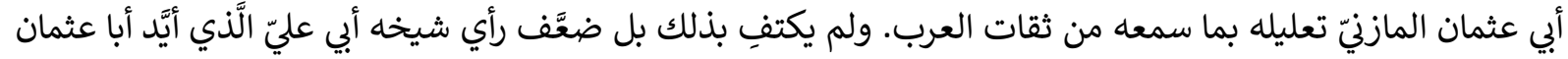

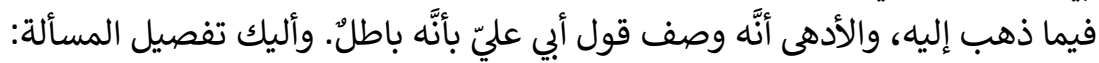

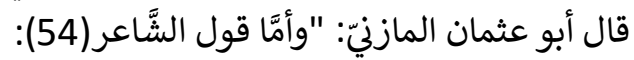

\section{كَفِعلِ الهِرِّ يَلتَمِسُ العَظَايَا.

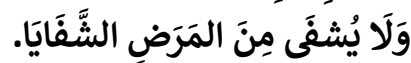

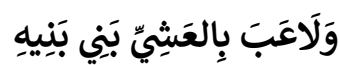

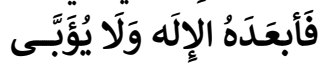

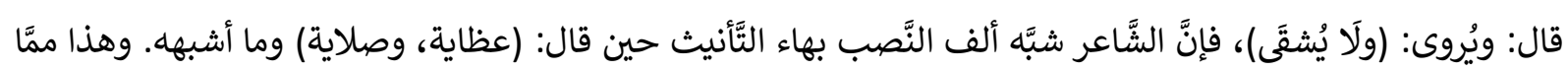

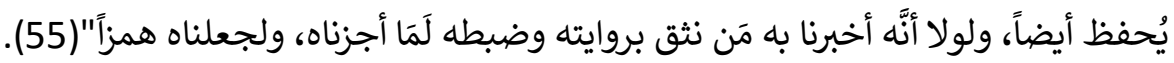

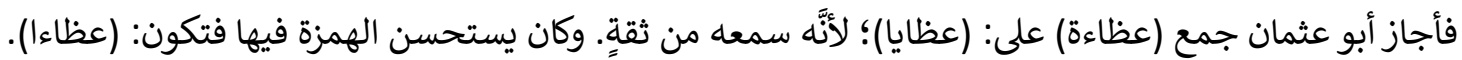

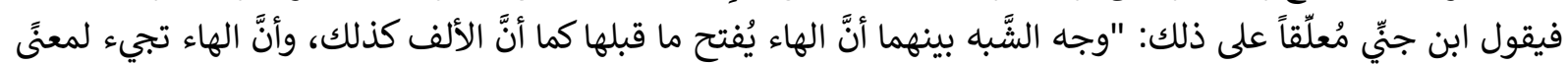

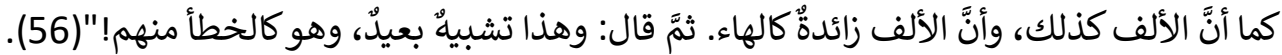

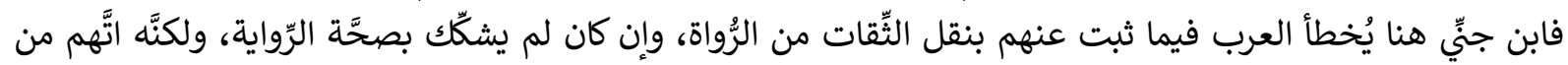

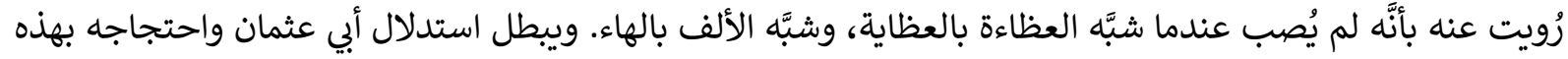

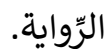
ثمَّ يذكر تعليقاً لأبي عليّ على هذه الرّواية فيقول: "قال أبو عليّ: والفرق بين الهاء والألف: لزوم الهاء، وزوال

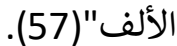

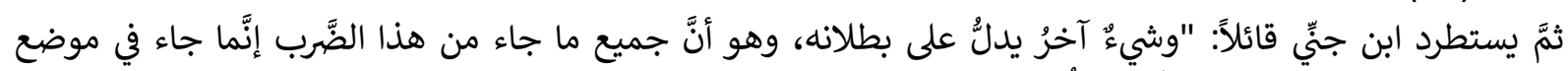
النَّصب، نحو قول الآخرِي(

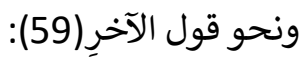

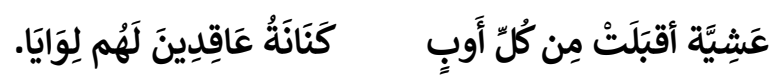
وكذلك جميع ما جاء منه، فهذا يُقوِي أنَّ الألف للنَّصب بمنزلتها من قولهم: (رأيتُ زيداً) وهذا واضحٌ جليُّ" (60).

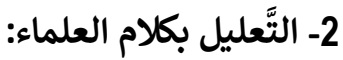

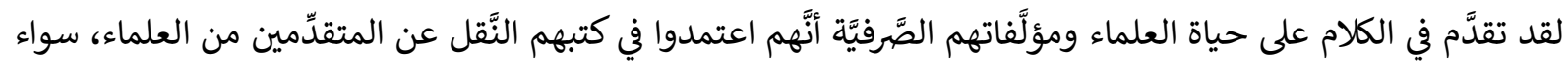

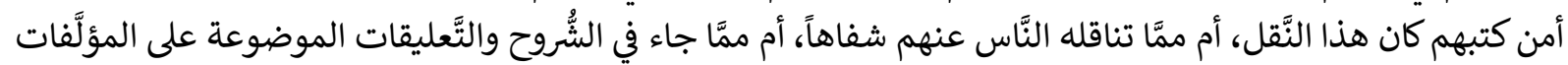
النَّحويَّة والصَّرفيَّة.

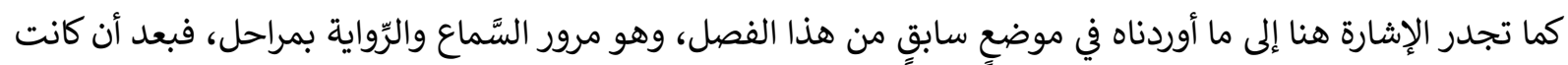

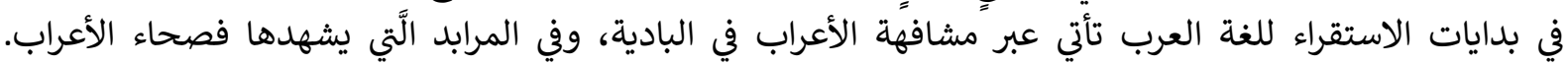

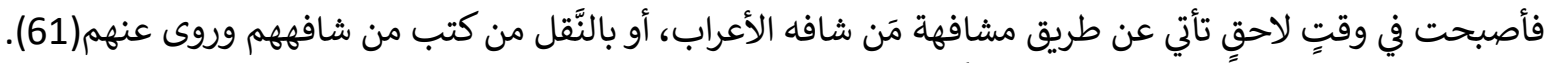

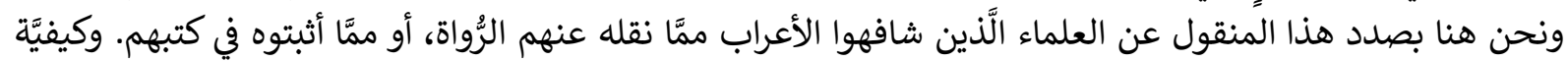
التَّعليل والاحتجاج بكلامهم في المؤلَّفات الصَّرفيَّة. 


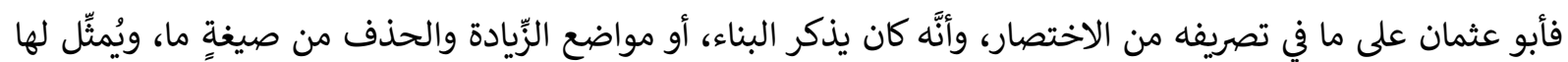

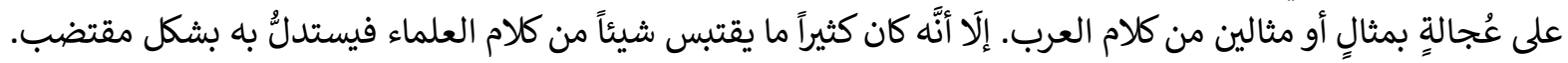

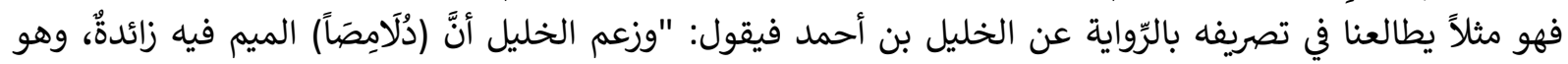

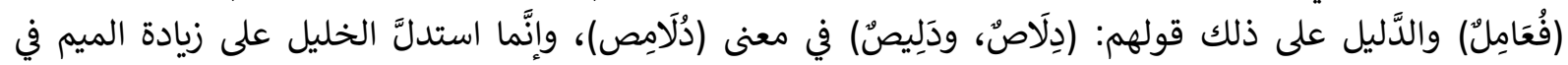

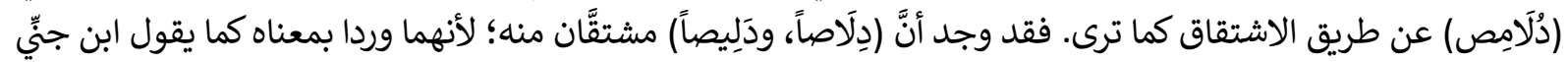
في تعليقه على المسألة"(62).

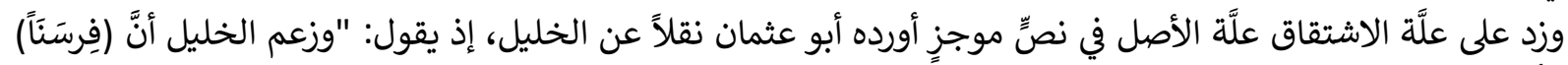

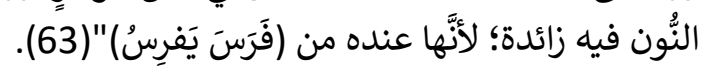

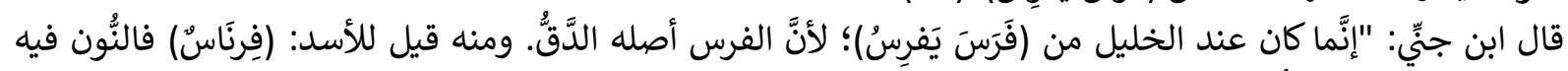

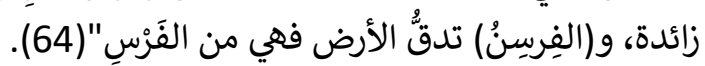

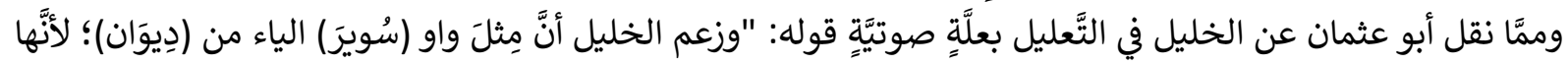

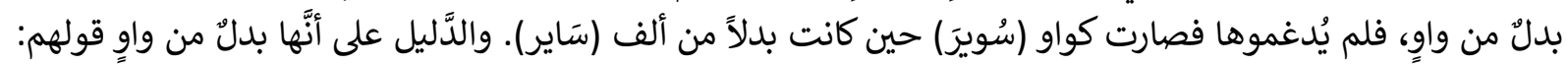

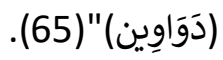
والمراد من قولها (َّله أن ياء (ديوان) مثل واو (سوير): أنَّ الألف في (سَاير) لمَّا قُلبت واواً صارت مدَّةً. وكذلك الواو في (دِووَان)

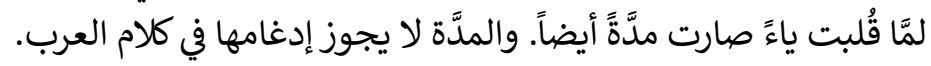

\section{الخحاتمـة}

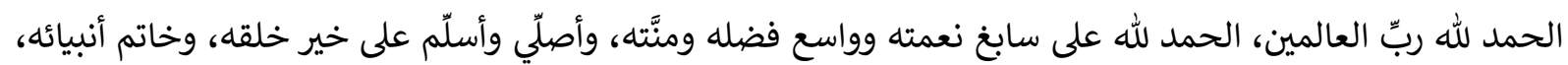

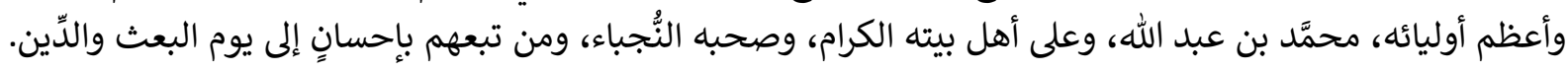

فبعد أنْ فرغت من هذا البحث الموجز توصَّلتُ إلى بعض النتائج أو الاستنتاجات، التَّي كان لا بدَّ من إثباتها هنا ليكتمل

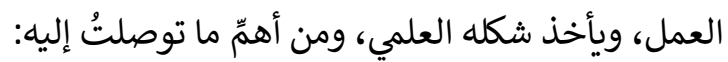
1- أصالة التَّعليل عند العرب، وعناية القدماء من علماء العربيَّة به، ووقوفهم عليه فيما كانوا ينقلونه من الرِّواية

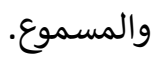

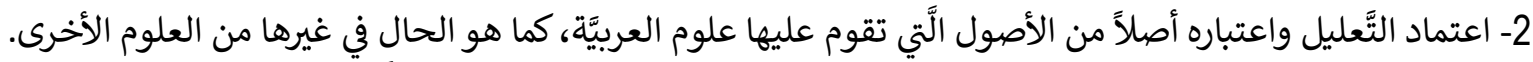

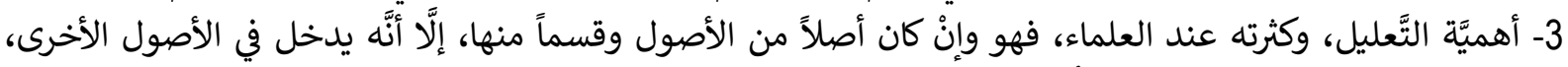

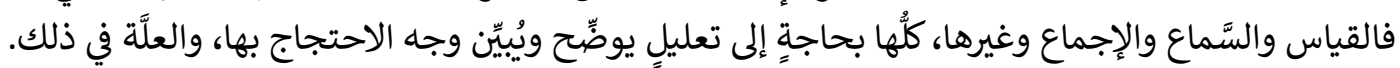

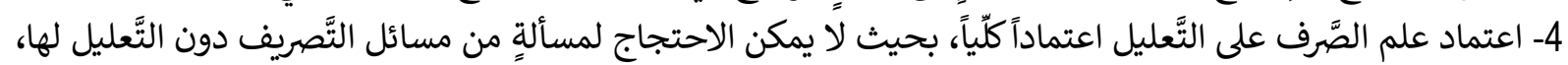
وبيان وجه العلَّة منها.

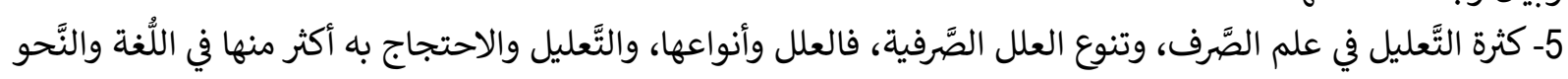

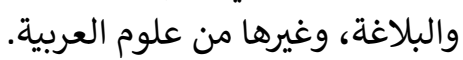

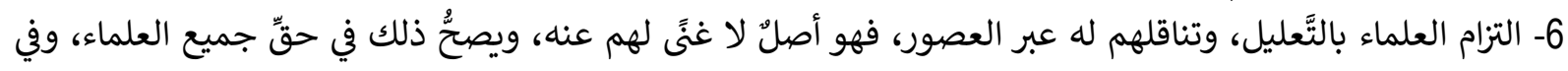
مختلف العصور والأزمنة، وحتَّى يومنا هذا. 
أدب الكاتب، تأليف: أبي محمَّد عبد الله بن مسلم بن قتيبة الدينوريّ المتوفَّى سنة (276هـ)، تحقيق: محمَّد الدالي، مؤسسة الرسالة، بيروت.

الاقتراح في أصول النَّحو، تأليف: جلال الدّّين، عبد الرَّحمن بن أبي بكر السُيوطيّ المتوفَّى (911هـ)، حقَّقه وشرحه:

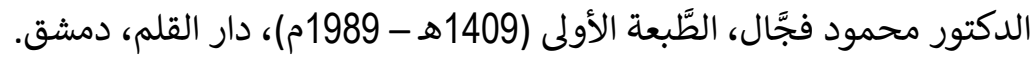

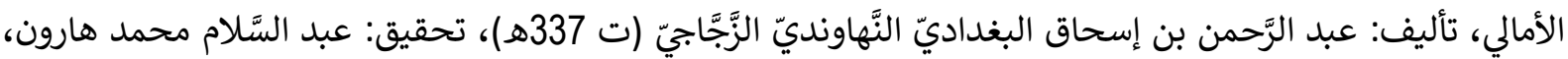
دار الجيل - بيروت، طيد أستون (1407هـ - 1987م).

البداية والنهاية، تأليف: أبو الفداء إسماعيل بن عمر بن كثير القرشي البصري ثم الدمشيقي المتوفى سنة (774هـ)، تحقيق: علي شيري، دار إحياء التراث العربي.

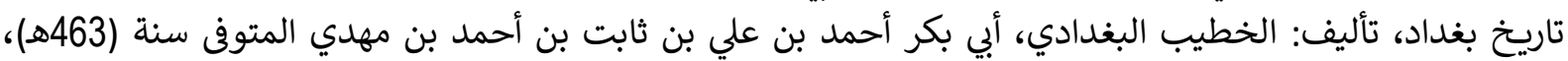

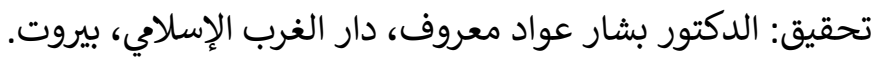

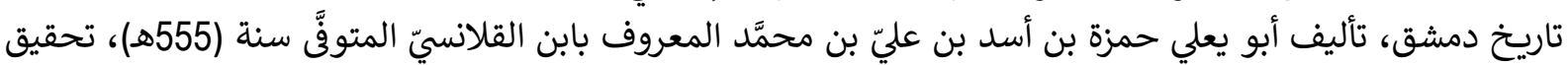

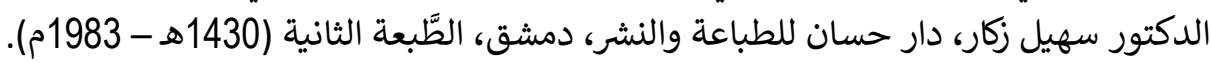

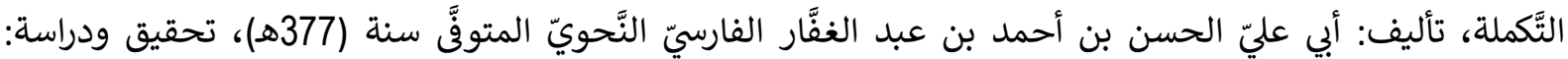

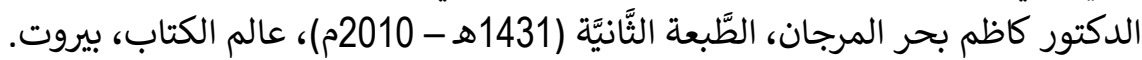

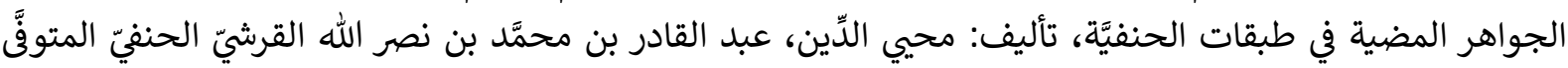

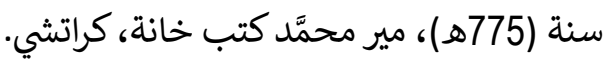

حاشية الخضري على شرح بن عقيل على ألفية بن مالك، شرحها وعلَّق عليها: تركي فرحان المصطفى، دار الكتب العلمية - بيروت.

الحور العين، تأليف: نشوان بن سعيد الحميريّ اليمنيّ (ت 573هـ)، تحقيق: كمال مصطفى، مكتبة الخانجي - القاهرة،

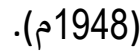

خزانة الأدب وغاية الأرب، تأليف: تقي الدّين أبي بكر بن عليّ بن عبد الله بن حجَّة الحمويّ (ت 837هـ)، تحقيق: عصام

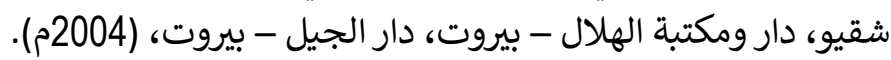

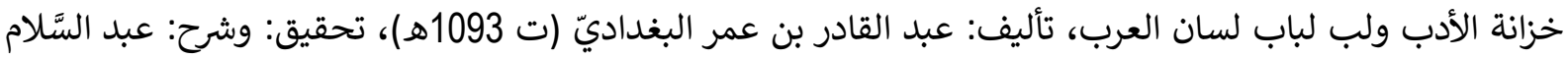

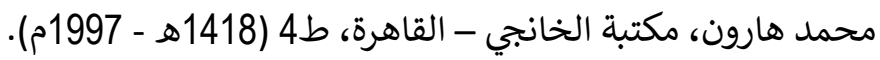

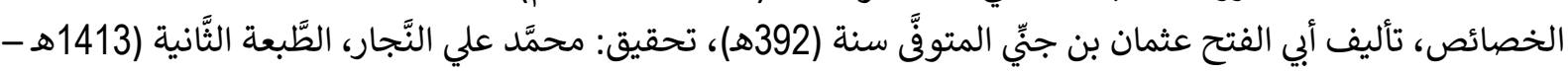

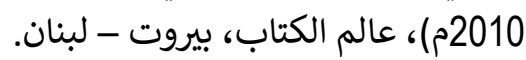

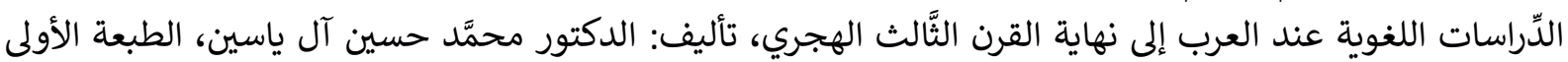

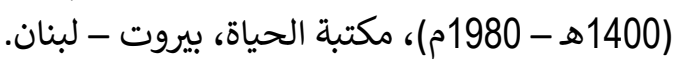

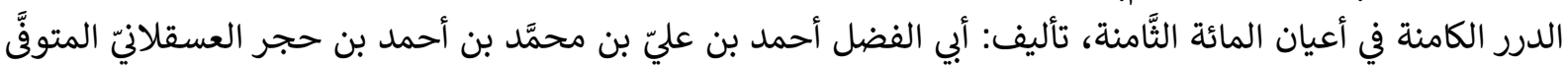

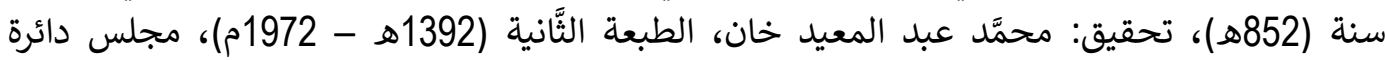

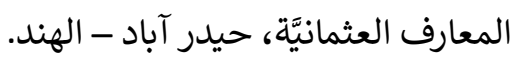

دقائق التصريف، تأليف: أبو القاسم بن محمد بن سعيد المؤدب المتوفى سنة (338هـ)، تحقيق الأستاذ الدكتور حاتم الفينة

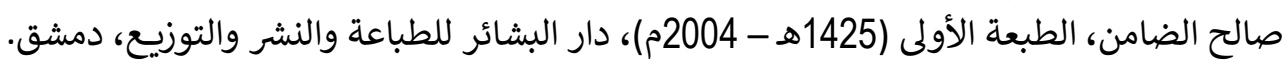

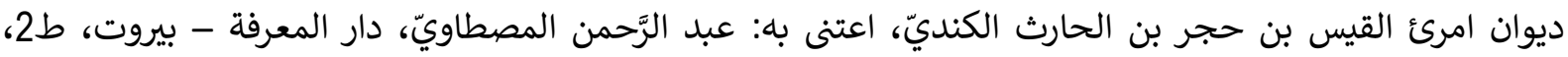
2004م) - 1425)

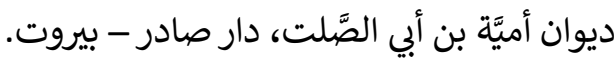

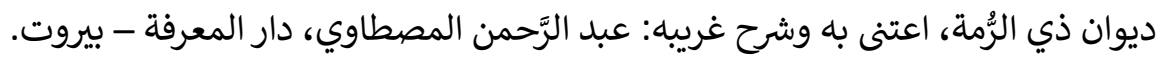

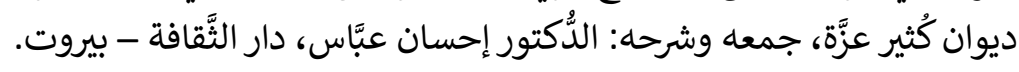

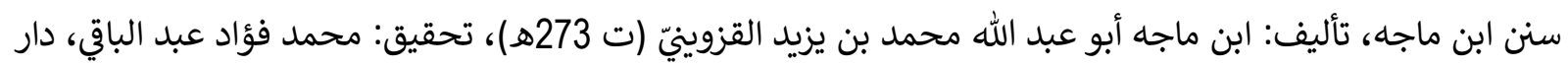
إحياء الكتب العربية - فيصل عبَّاس البابيّ الحلبيّ. 
السُّنن الكبرى، تأليف: أبي بكر أحمد بن الحسين بن عليّ بن موسى الخسرو جرديّ الخراسانيّ (ت 458هـ)، تحقيق:

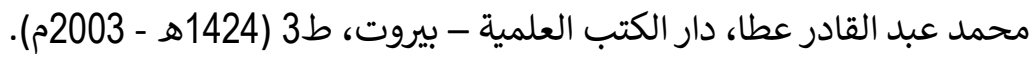

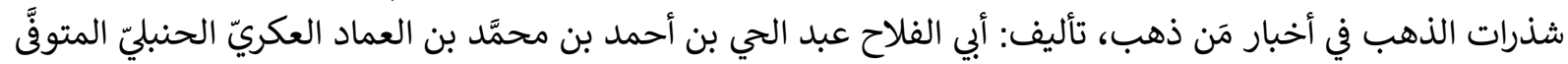

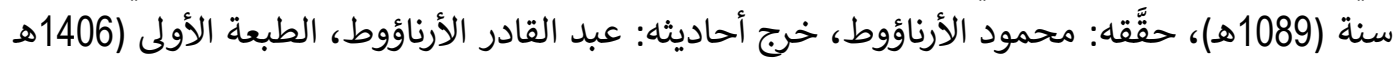

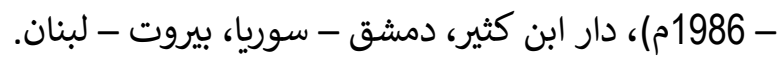

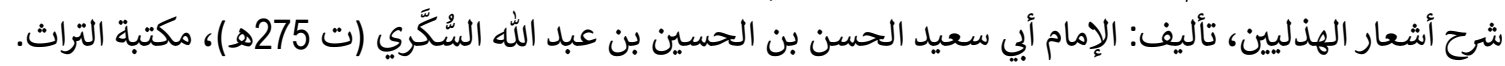

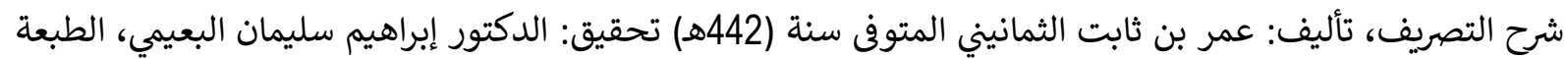

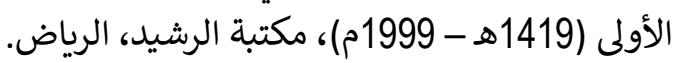

الشعر والشعراء، تأليف: أبي محمَّد عبد الله بن مسلم بن قتيبة الدَّينوريّ (ت 276هـ)، دار الحديث - القاهرة،

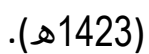

الصِّناعتين، تأليف: أبي هلال الحسن بن عبد الله بن سهل بن سعيد بن يحيى بن مهران العسكريّ (ت 395هـ)، تحقيق:

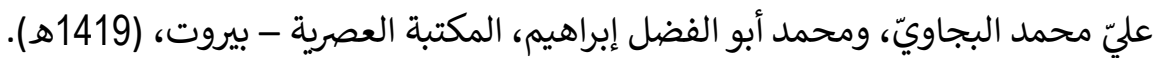

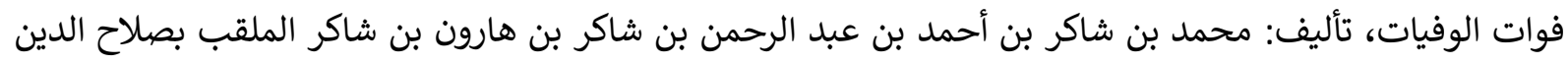

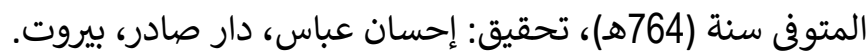

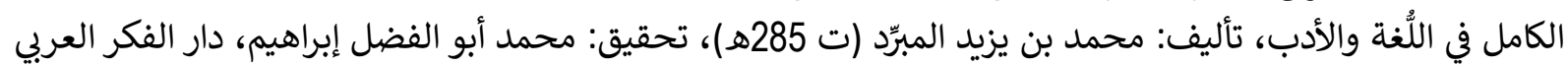

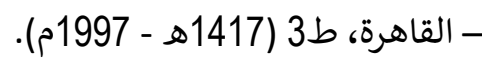

الكتاب، تأليف: سيبويه، أبي بشر عمرو بن عثمان بن قنبر المتوفَّ سنة (180هـ)، تحقيق وشرح: عبد السلام محمَّد

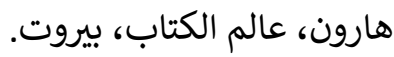

مجمع الأمثال، تأليف: أبي الفضل أحمد بن محمد بن إبراهيم الميدانيّ النَّيسابوريّ (ت 518هـ)، تحقيق: محمد محيي

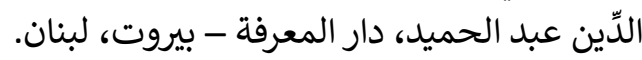

المدارس النَّحويَّة، تأليف: الدكتورة خديجة الحديثي، الطَّبعة الأولى (1434هـ - 2012م)، مؤسَّسة الرَّافدين للمطبوعات،

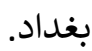

المدارس النَّحويَّة، تأليف: شوقي ضيف (أحمد شوقي عبد السَّلام ضيف) المتوفَّى سنة (1426هـ)، دار المعارف، القاهرة.

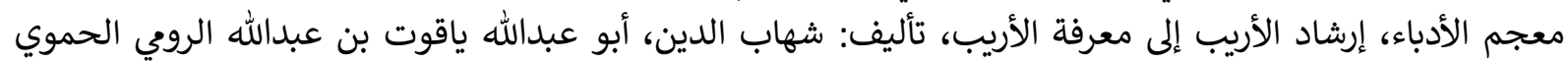

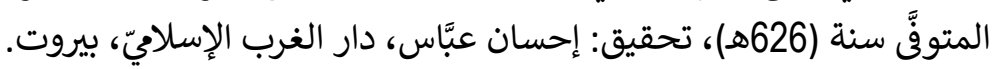

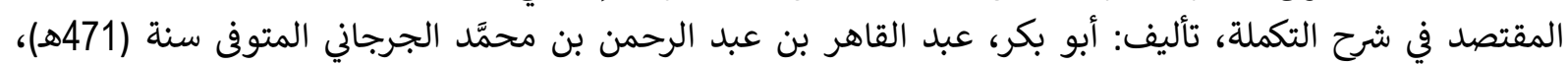

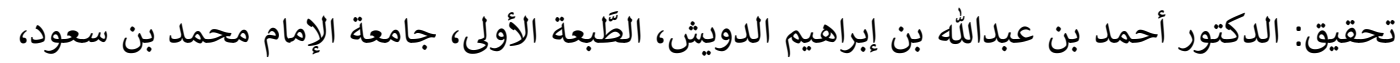

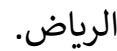

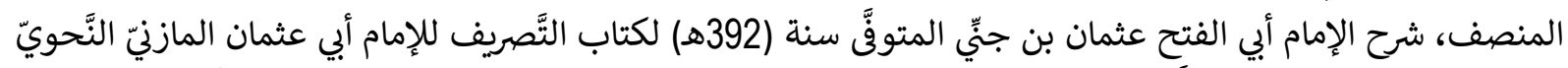

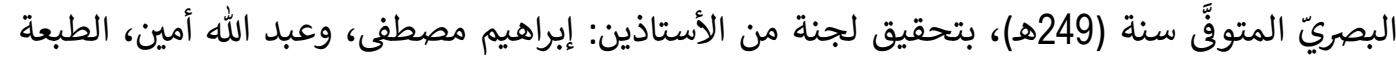

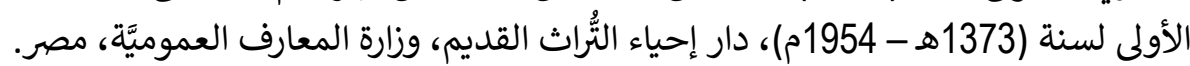
الوافي بالوفيات، تأليف: صلاح الدين خليل بن أيبك بن عبد الله الصفدي المتوفى سنة (764هـ)، تحقيق: أحمد

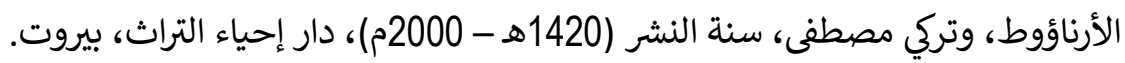


(1) الدراسات اللغوية عند العرب إلى نهاية القرن الثالث، 68 الثرك،

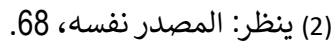

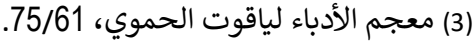

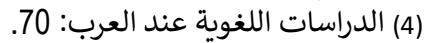

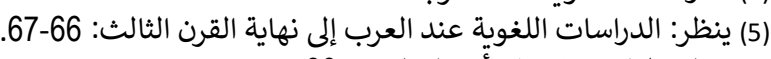

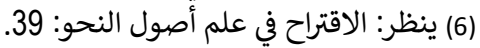

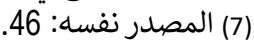

(8) المصدر نفسه: 47.

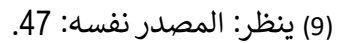

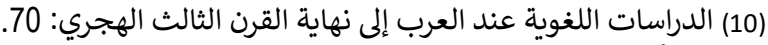

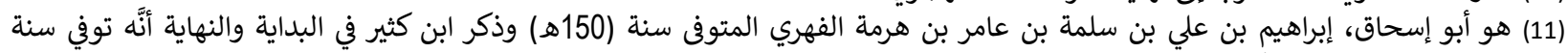

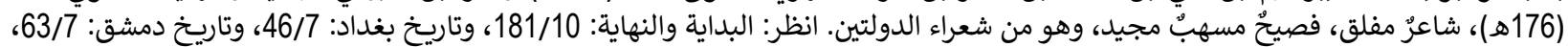

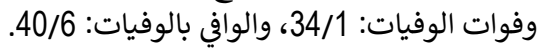
(12) ينظر: الاقتراح: 56.

(13) المدارس النحوية، شوقي ضيف:

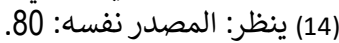

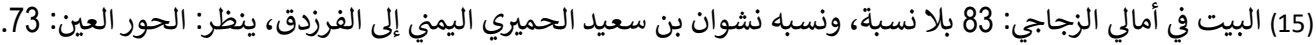

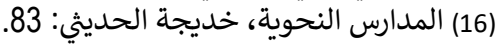
(17) الكتاب: 264/3.

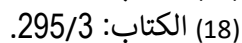

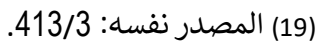
(20) المصدر نفسه: 431/3.

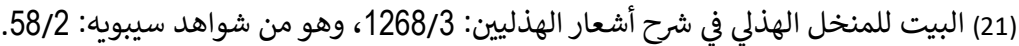

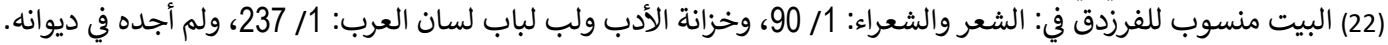

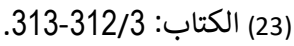

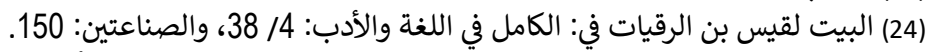

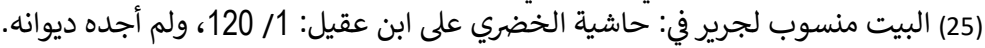
(26) الكتاب: 3/ 313-314.

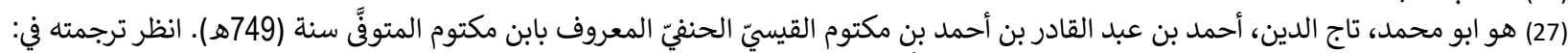

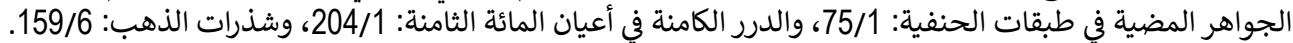

(28) الاقتراح في علم أصول المبن فيقات النحو: 89.

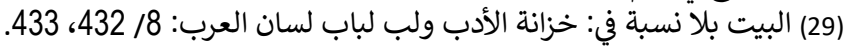
(30) المنصف لابن جني: 129/1) (31) هذا عجز بيت احتج به بن المنين جني في منصفينه، ولم أجده في غيره، ينظر: المنصف لابن جني: 1/ 166.

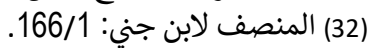

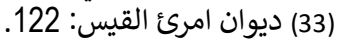

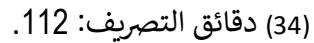

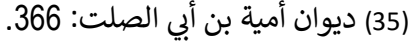

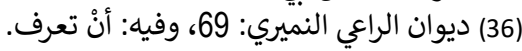

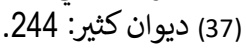

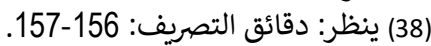
(39) (39) ديوان ذي الرمة: (40) البيت منسوب للفرزدق في: خزانة الأدب ولب لباب لسان العرب: 18/ 212، 213، ولم أجده في ديوانه.

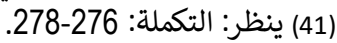

(42) ينظر: المنصف لابن جني: 63/1.

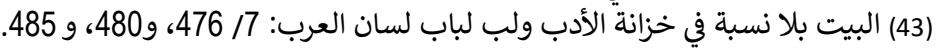

(44) المنصف لابن جني:

(45) سورة يوسف، من الآية: 36 المنين

(46) البيت بلا نسبة في: أدب الكبة: الكاتب: 275)، ومجمع الأمثال: 11/ 213.

(487) شرح التصريف: 284-285.

(48) المنصف لابن جني: 114/1 التصريف:

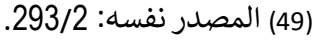

(50) الحديث في: سنن ابن ماجه: 1931/ 502، رقم الحديث: (1587)، والسنن الكبرى للبيهقي: 4/ 129، رقم الحديث: (7201).

(51) دقائق التصريف:

(52) (52) التكملة: 247-248.

(53) المقتصد في شرح التكملة: 305/1 النملة: 
International Journal of Education and Language Studies

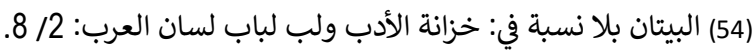

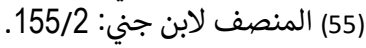

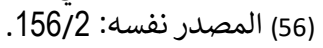

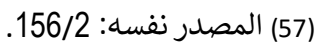

(58) هذا صدر بيت ورد منسوبا لكثير في: الخصائص لابن جني: 2/2 348، ولم أجده في ديوانه.

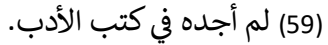

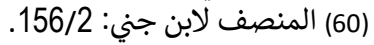

(61) (621) ينظر: الدراسات التلغوية عند العرب إلى نهاية القرن الثالث: 66.

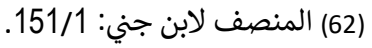

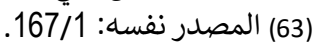

(65) المصدر نفسه: 167/1. وينظر: 167/1/21/2 دقائق التصريف: 358.

(65)65) المنصف لابن جني: 31/2. 